\title{
Glycans in autophagy, endocytosis and lysosomal functions
}

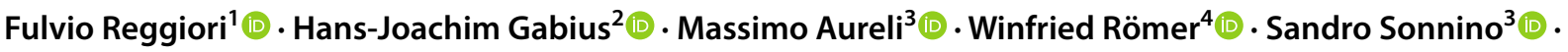 \\ Eeva-Liisa Eskelinen ${ }^{5}$
}

Received: 9 May 2021 / Revised: 14 June 2021 / Accepted: 17 June 2021 / Published online: 14 August 2021

(c) The Author(s) 2021

\begin{abstract}
Glycans have been shown to function as versatile molecular signals in cells. This prompted us to look at their roles in endocytosis, endolysosomal system and autophagy. We start by introducing the cell biological aspects of these pathways, the concept of the sugar code, and provide an overview on the role of glycans in the targeting of lysosomal proteins and in lysosomal functions. Moreover, we review evidence on the regulation of endocytosis and autophagy by glycans. Finally, we discuss the emerging concept that cytosolic exposure of luminal glycans, and their detection by endogenous lectins, provides a mechanism for the surveillance of the integrity of the endolysosomal compartments, and serves their eventual repair or disposal.
\end{abstract}

Keywords Endolysosomal system · Glycoproteins · Glycolipids · Glycoconjugates · Lectins · Sugar code

\section{Introduction}

\section{The routes to lysosomes: endocytosis and autophagy}

Lysosomes are intracellular, acidic organelles surrounded by a single membrane, in which the catabolic processing of macromolecules takes place. They were described for the first time by Christian de Duve in the 1950s [1, 2]. Lysosomes are ubiquitously distributed in all eukaryotic cells and appear, by electron microscopy, as dense cytosolic bodies of heterogeneous size and morphology, mainly localized in the perinuclear region of the cell. The degradative roles of lysosomes strongly rely on distinct transport routes that allow cargo delivery into their interior from both intracellular and extracellular locations. Some of these trafficking pathways are also involved in the transport of resident enzymes and other (glyco)proteins that are essential for lysosomal functions.

After synthesis in the endoplasmic reticulum (ER), lysosomal (glyco)proteins traverse the Golgi complex to enter the trans Golgi network (TGN), from where the majority of soluble lysosomal enzymes and lysosomal membrane proteins (LMPs) are transported to the endolysosomal system (Fig. 1). Most of the soluble lysosomal enzymes interact with sorting receptors to enter clathrin-coated vesicles traveling directly from the TGN to the early endosomes (EEs). This sorting step requires the heterotetrameric adaptor protein 


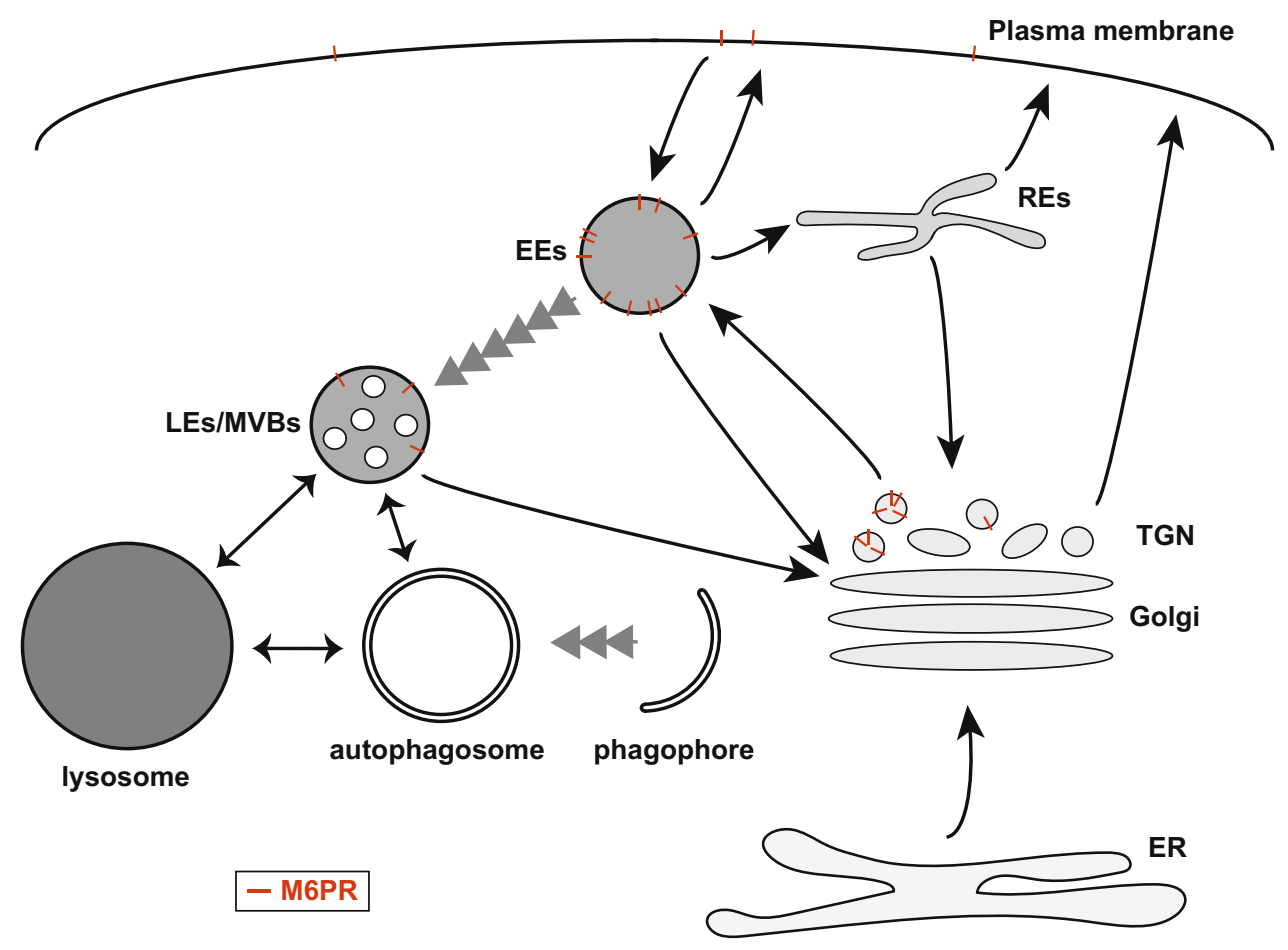

Fig. 1 Simplified overview of the secretory and endolysosomal systems, and the principal glycoprotein transport routes. The synthesis of signal-peptide marked soluble and transmembrane (glyco)proteins on the rough endoplasmic reticulum (ER) leads to their translocation into the ER lumen or membrane, respectively. While some of the nascent proteins possess retention signals to let them remain localized in this compartment, others are transported to their final destination through sorting mechanisms that rely on the presence and/or absence of targeting signals that are encoded in peptide motifs and glycans. Integral plasma membrane and secreted (glyco)proteins reach the cell surface by vesicular traffic, passing through the Golgi. Endocytosed (imported) (glyco)proteins are delivered to the early endosomes (EEs), which are also the principal arrival point for newly synthesized (glyco)proteins destined to the endolysosomal system, sorted out from the secretory pathway at the trans-Golgi network (TGN). EEs are an important hub for (glyco)protein sorting and distribution. Lysosomal protein-sorting receptors can be recycled from EEs back

complex 1 (AP-1) and the Golgi-localized, $\gamma$-ear-containing and ARF-binding (GGA) proteins, which recognize specific motifs in the cytosolic tail of the sorting receptors and promote the subsequent formation of clathrin-coated vesicles [3-5]. The clathrin-coated vesicles can also sort LMPs from TGN to EEs [6]. In addition, a clathrin-independent transport route that delivers LMPs, but not sorting receptors, directly from the TGN to LEs has been discovered (Fig. 1) $[7,8]$. Newly synthesized lysosomal enzymes and LMPs that escape sorting in the TGN enter the default secretion pathway to the plasma membrane and are targeted to lysosomes via endocytosis (Fig. 1). Low levels of the sorting receptors at the plasma membrane thereby mediate the endocytosis of the secreted hydrolases [9]. Although these transport routes are mainly biosynthetic, non-functional proteins can to the Golgi for re-use, while plasma membrane proteins can be trafficked to the plasma membrane directly or via recycling endosomes (REs). Lysosomal soluble and transmembrane (glyco)proteins, however, remain associated with the EEs, and reach lysosomes through the maturation of EEs into late endosomes/multivesicular bodies (LEs/MVBs), which are characterized by the formation of intraluminal vesicles. LEs/MVBs finally fuse with lysosomes to deliver their membrane-associated and luminal cargos to this organelle. Autophagosomes arise through the generation and expansion of a phagophore, and when complete, they fuse either first with LEs and then lysosomes or directly with lysosomes. Arrows indicate the direction of main transport routes. Double-head arrows highlight fusion events between organelles. Serial arrowheads designate maturation processes. The Man-6-phosphate receptors (M6PRs, red bars) are highlighted in the compartments through which they are trafficking. M6PRs are mostly present in the TGN and EEs, but they can also be detected at the plasma membranes and LEs/MVBs

be recognized in the Golgi and ubiquitinated to be diverted into the endosomal system for lysosomal degradation [10]. Moreover, there are also transport pathways that directly transport proteins from the ER to LEs/lysosomes for turnover, to eliminate regulators of the ER associated degradation [11] or proteasome-resistant polymers of $\alpha 1$-antitrypsin Z polymers [12].

Endocytosis is the major cellular pathway for internalization of extracellular material and begins with the formation of an endocytic vesicle (Fig. 1). There are several distinct subtypes of endocytic vesicles that bud from the plasma membrane and mediate entry into the cell. These differ by cargo and machinery, and include dynamin- and/or clathrindependent and independent pathways [6]. The commonly accepted model is that endocytic vesicles subsequently fuse 
with each other or directly with pre-existing EEs (Fig. 1). Ras-associated binding (RAB) GTPases are small monomeric $\mathrm{G}$ proteins that can switch between an active (GTPloaded) and an inactive (GDP-loaded) state, which provide the means to spatially and temporally control intracellular traffic and signaling, but also organelle identity. EE-localized RAB5 is considered the master regulator of the endocytic pathway and exerts its action by attracting a variety of effector proteins $[13,14]$. While soluble endocytosed cargos localize in the EE lumen, internalized integral membrane cargo (glyco)proteins destined for degradation in lysosomes, such as the epidermal growth factor and growth hormone receptors, are retained in the EEs by their incorporation into intra-luminal vesicles that form through the budding of the endosomal limiting membrane. Intra-luminal vesicle formation starts in the EEs and continues in LEs (Fig. 1) [14]. The process of cargo selection and intra-luminal vesicle formation involves the ubiquitin-dependent endosomal sorting complexes required for transport (ESCRT) complexes, but also other mechanisms have been described [6]. EEs mature into LEs through a mechanism that involves multiple rounds of membrane fusion and fission during which the protein and lipid composition of the EEs change as they acquire more intra-luminal vesicles (Fig. 1). Since LEs contain numerous intra-luminal vesicles, they are often also termed multivesicular bodies (MVBs). During the EE to LE maturation, RAB5 is replaced by RAB7 and the phosphoinositide phosphatidylinositol-3-phosphate (PI3P) is converted into phosphatidylinositol-3,5-biphosphate through phosphorylation [15, 16]. Moreover, soluble lysosomal enzyme-sorting receptors and other transmembrane proteins like soluble $N$-ethylmaleimide-sensitive factor attachment protein receptors (SNAREs) can be returned to the plasma membrane or transported to either the recycling endosomes (REs) or the TGN for reuse. LEs/MVBs can fuse with other LEs/MVBs or with lysosomes (Fig. 1) [14]. REs are generally identified by the presence of RAB4 and RAB11, and consist of a network of branched tubules with multiple (clathrin-coated) buds, which form exits from which cargo proteins can travel to distinct cellular destinations (Fig. 1) [14]. While most pathways emerging from REs divert from the degradative track and deliver proteins either to the plasma membrane or the TGN, RE can also be an intermediate station en route to the lysosomes since transmembrane proteins can be transported to the LEs/lysosomes in an adaptor protein AP-3-dependent manner (Fig. 1) [17].

Autophagic pathways deliver cytoplasmic material and organelles to lysosomes for degradation and recycling; the degradation products are exported from the lysosomes back to cytoplasm to be used as building blocks in biosynthetic processes and/or for energy production. Autophagy is an evolutionarily conserved catabolic process that supports the survival of eukaryotic cells during starvation but also other stresses. There are three distinct routes from the cytoplasm to lysosomes, which are called macroautophagy, microautophagy and chaperone-mediated autophagy. In macroautophagy, often simply referred to as autophagy, the cytoplasmic cargo is first sequestered into double-membrane vesicles called autophagosomes and then transported to lysosomes for degradation by fusion of the autophagosomal outer limiting membrane with a lysosome (Fig. 1) [18]. In microautophagy, the lysosomal or endosomal limiting membrane internalizes small portions of cytoplasm by invagination and subsequent pinch off, a process that leads to the formation of internal vesicles. These are eventually degraded with the cargo. In chaperone-mediated autophagy, a subclass of cytoplasmic proteins that have a KFERQ-like amino acid motif are first recognized by a cytosolic chaperone heat shock cognate $71 \mathrm{kDa}$ protein (HSC70). The chaperone-cargo complex then interacts with lysosomal-associated membrane protein 2A (LAMP2A) on the lysosomal membrane, before the cargo protein is transported, in an unfolded state, through the lysosomal membrane [19]. Autophagy has diverse roles in cellular housekeeping including removal of damaged organelles, intracellular pathogens and harmful aggregates $[20,21]$. Studies in several model organisms show that functional autophagy extends lifespan, which is likely connected to the prevention of metabolic stress and to the clearance of harmful proteins and worn-out organelles [22, 23]. Further, autophagy or its dysfunction have been implicated in many diseases including cancer, muscle and heart diseases, neurodegenerative and metabolic disorders, inflammation, and susceptibility to infections [24, 25]. Notably, autophagy may have both positive and negative effects on cancer progression, depending on the context [26-28].

Autophagosomes are formed by phagophores, flat membrane cisterns that elongate and curve into vesicles that are limited by two lipid bilayers (Fig. 2). Phagophore assembly is initiated when the unc-51 like autophagy activating kinase (ULK) complex, containing ULK1 or ULK2, autophagy-related 13 (ATG13), ATG101 and focal adhesion kinase family interacting protein of $200 \mathrm{kD}$ (FIP200), is recruited nearby the ER [29-31]. ULK1 is activated during amino acid starvation, when the amino acid and energy sensors mammalian target of rapamycin complex 1 (mTORC1) and AMP-activated kinase (AMPK) are inactivated and activated, respectively [32]. The ULK kinase complex in turn activates the phosphatidylinositol 3-kinase complex I through direct phosphorylation. This complex contains beclin 1 (BECN1), phosphatidylinositol 3-kinase catalytic subunit type 3 (PIK3C3/VPS34, a PI3P-kinase), phosphoinositide-3-kinase regulatory subunit 4 (PIK3R4/VPS15), nuclear receptor binding factor 2 (NRBF2) and ATG14L, which positions the complex adjacent to the ER. Localized synthesis of PI3P on the phagophore recruits PI3Pbinding proteins such as double FYVE-containing protein 


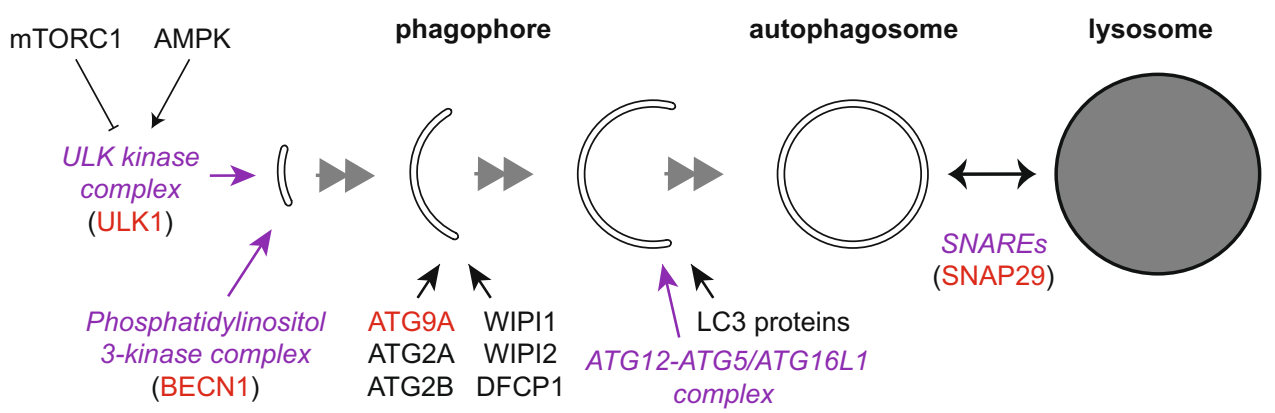

Fig. 2 Locations of key autophagy protein functions during autophagosome biogenesis. Purple italic font indicates protein complexes or functional clusters; proteins in parenthesis are parts of the complexes or clusters. Red font indicates proteins that are $\mathrm{N}$-glycosylated (autophagy-related 9A, ATG9A), or known to be regulated by GlcNAcylation (unc-51 like autophagy activating kinase, ULK1; beclin 1,

1 (DFCP1) and WD repeat domain, phosphoinositide interacting 1 (WIPI1) or WIPI2 that collectively lead to the formation of ER subdomains called omegasomes [33]. Autophagosome biogenesis occurs in, or next to, omegasomes. Via interaction with ATG16L1, WIPI2 recruits the ATG12-ATG5 conjugate, which forms large oligomers by first binding to ATG16L1 and then multimerizing [34]. The ATG12-ATG5-ATG16L1 complex determines the site where the members of the microtubule-associated light chain 3 (LC3) protein family are conjugated to phosphatidylethanolamine (PE). The generated LC3-II is needed for the recruitment of LC3 proteins to the phagophore for different functions, including the closure of the phagophore into an autophagosome. The conjugation reactions of ATG12 to ATG5 and LC3 proteins to PE are assisted by ATG7 and ATG10, and ATG7 and ATG3, respectively. Upon autophagosome completion, the LC3-II pool on the outer limiting membrane dissociates, while the LC3-II in the inner limiting membrane is delivered to the lysosome together with the cargo.

\section{Protein and lipid glycosylation}

The phylogenesis route to multicellular organisms has been paved by an increasing degree of sophistication of intracellular compartmentalization and vesicular transport. As outlined above, newly synthesized (glyco)proteins can reach intracellular compartments like lysosomes or the plasma membrane from the ER. The glycoproteins present in intracellular compartments are luminal or integrated into membranes, with their glycans mostly facing the lumen. Molecular signals for damage and 'postal codes' for reliable segregation ensure the intracellular system's proper functioning. Thus, efficient surveillance mechanisms are needed to spot the glycans as indicators of intracellular membrane damage and subsequently, to initiate repair or removal by
BECN1 and synaptosome associated protein 29, SNAP1 29). mTORC1 mammalian target of rapamycin complex 1; AMPK AMP-activated kinase; ATG2, 12, 5, 16L1 autophagy-related 2, 12, 5, 16L1; DFCP1 double FYVE-containing protein 1; LC3 microtubule-associated light chain 3

degradation. Here glycans with their exceptional talents come into play.

In contrast to nucleic acids and proteins, the linear sequence of a glycan, for example the disaccharide lactose composed of galactose (Gal)-glucose (Glc), is insufficient to define its structure. In addition, glycans are attached to carriers in a versatile manner to generate glycoproteins and glycolipids, underscoring the assumption of broad-scale versatility [35-37]. More information is required to define the structure of a glycan, i.e. on the position of the connecting glycosidic bond on both sugar units, and the nature of anomery ( $\alpha$ or $\beta$ ). Adding this information turns Gal-Glc into Gal $\beta 1,4 \mathrm{Glc}$ to precisely define lactose, since this sugar is just one of the Gal-Glc-based disaccharides. These two structural parameters let glycans give an unsurpassed diversity among biomolecules, which upholds the use of the word complex carbohydrates [38], and explains why they are much more complex, variegated and difficult to study than proteins or nucleic acids [39]. In terms of encoding biological information, however, the possibility to generate a large panel of molecular signals by a small set of letters is ideal to generate a glycan-based mode of intraand intercellular communication [40, 41]. Thus, sugars can be viewed as the third alphabet of life, following nucleotides and amino acids as the first and second letter sets.

In the context of intracellular trafficking, the sugar code is expected to be ubiquitous in eukaryotes, to require a highly organized and dynamically regulatable enzymatic machinery and to make the tagged proteins available for packaging into vesicles. All these expectations are entirely fulfilled by the co- and posttranslational route of $N$-glycosylation. It begins at the main entry site of the cellular membrane system, the ER, and proceeds in the Golgi apparatus, before the acceptor (glyco)proteins arrive at their final destination, which can be one of these 
organelles but also the plasma membrane or one of the compartments of the endolysosomal system [42-49]. The $\mathrm{N}$-glycans of glycoproteins (and also other types of protein glycosylation) are thus a highly versatile biochemical modification to store biological information. In order to translate the information of glycan-encoded signals into a distinct bioactivity, this has to be red by sugar-specific receptors called lectins, a term derived from Latin legere [50] (for overviews of lectin history, classification and occurrence, please see [51, 52]). Since more than a dozen protein folds have developed the ability to bind glycans, and the encoding genes were platforms for duplications and intrafamily diversifications [53,54], the versatility of glycan structure is matched by a large diversity in lectins with different glycan binding specificities. In fundamental terms, oligosaccharides can readily convey biorelevant information through their interplay with lectins.

Mono- and/or oligosaccharides are attached to proteins mostly through linkage to Ser/Thr or Asn residues, to lead to the so-called $O$ - and $N$-glycosylations, respectively. Their biosynthesis, however, differs. While the constituents of $O$-glycans are added step-wise, $\mathrm{N}$-glycan synthesis starts by a block-wise transfer. In particular, $\mathrm{N}$-glycans are preassembled as a $14 \mathrm{mer}$ oligosaccharide $\left(\mathrm{Glc}_{3} \mathrm{Man}_{9} \mathrm{GlcNAc}_{2}\right)$ on a dolichol carrier initially on the cytoplasmic surface of the ER membrane, which subsequently translocates into the luminal side of the ER [55]. Once on the protein, this $\mathrm{N}$-glycan is trimmed down stepwise to a heptasaccharide $\left(\mathrm{Man}_{5} \mathrm{GlcNAc}_{2}\right)$ in the ER, and finally re-elongated into the diversity of mature $\mathrm{N}$-glycans by a series of glycosylation steps taking place in the Golgi cisternae [55]. Nine different types of $O$-glycosylation are found on proteins trafficking through the secretory pathway in vertebrates, and most $O$-glycans are further elongated/branched in the Golgi by sequential addition of monosaccharides by distinct enzymes [56]. $O$-Linked protein glycosylation can also take place on nuclear and cytosolic proteins. This is a dynamic event in which a monosaccharide such as fucose (Fuc) or $\mathrm{N}$-acetylglucosamine (GlcNAc), which does not get branched, is added in a process called GlcNAcylation, and removed from protein in a regulated manner to modulate its function [57-60].

Saccharides can also be linked to sphingolipids, yielding the broad class of glycosphingolipids (GSLs). The process starts with addition of a monosaccharide to a ceramide moiety, and such a small headgroup is already bioactive [61-63]. The sequential addition of monosaccharides leads to the formation of GSLs [64]. This class of lipids resides principally at the plasma membrane and reaches this location through the secretory pathway. Like in the case of the $N$-glycans, GSL glycans are generated and extended in the lumen of the ER and Golgi, leading to a topological distribution of GSL on the extracellular side of the plasma membrane [64]. Another lipid class that contains a glycan core are the glycosylphosphatidylinositol (GPI)-anchors [65, 66]. Those are assembled on phosphatidylinositol moieties with the sequential addition of one GlcNAc and four mannoses (Man), but also ethanolamine groups, in the ER lumen [65]. GPI-anchors are conjugated to the C-terminus of a subset of newly synthesized (glyco)proteins translocated in the ER, which initially have a transient hydrophobic C-terminal peptide that is later removed. GPI-anchoring allows soluble proteins both to be associated to membranes and to reach the plasma membrane through the secretory route. GPI-anchored (glyco) proteins face the extracellular milieu at the plasma membrane [65].

\section{Glycans and lysosomes}

\section{Lysosomal proteins are glycosylated}

Lysosomes, as noted above, are delimited by a single membrane with a thickness of 7-10 nm, which is characterized by a continuous luminal glyco-layer generated by the presence of highly glycosylated LMPs [67]. It was originally suggested that the coating by sugars could have a protective role against the catabolic action of lysosomal hydrolases, but it has also become clear that the saccharide moieties are fundamental for the proper function of the LMPs in lysosomal motility, transport of catabolites across the membrane, and fusion processes occurring between lysosomes and others intracellular organelles and plasma membrane $[68,69]$. Among LMPs, the most abundant are LAMP1 and LAMP2, which are characterized by more than 25 glycosylation sites and considered as lysosomal marker proteins. Interestingly, the glycan panel of these proteins contains $O$-glycan chains with $\mathrm{N}$-acetyllactosamine repeats and sialyl $\operatorname{Le}^{\mathrm{x}}\left(\mathrm{sLe}^{\mathrm{x}}\right)$ termini, which are known to interact with cell adhesion molecules such as selectins [70]. In addition, $N$ - and $O$-glycans are modified in almost equal efficiency to express $\mathrm{sLe}^{\mathrm{x}}$ structures, suggesting that both $\mathrm{O}$-glycans and $\mathrm{N}$-glycans contribute to the expression of sialyl Le ${ }^{\mathrm{x}}$ structures in LAMP proteins [71]. LAMP1 and LAMP2 represent $50 \%$ of all membrane proteins of the lysosomal membrane. Another important protein associated with the lysosomal membrane is the multisubunit vacuolar ATPase proton pump, which is responsible for the acidification of the lysosomal lumen [72]. Acidic intra-lysosomal $\mathrm{pH}$ is essential for the activation and function of the lysosomal enzymes. Lysosomes contain about 60 different acidic hydrolases involved in the degradation of specific substrates. They are mainly soluble except for those involved in the lipid catabolism, which are principally associated with the lysosomal membrane. 
Lysosomal enzymes are members of several classes of proteins such as proteases, glycosidases, phosphatases, sulphatases, lipases, and nucleases. This variety reflects the capability of the lysosomes to degrade multiple types of macromolecules, including proteins, membranes, nucleic acids and all kinds of glycoconjugates [73].

\section{Lysosome biogenesis is regulated by TFEB}

Recent evidence supports the role of the transcription factor EB (TFEB) as master regulator in the transcriptional control of lysosomal hydrolases [74]. TFEB belongs to the microphthalmia family of basic/helix-loop-helix/ leucine zipper transcription factors (MiT family) [75, 76]. In particular, TFEB directly binds to a common 10-base E-box-like palindromic sequence of DNA called coordinated lysosomal expression and regulation (CLEAR) motif, which is found in one or more copies in the promoter of several genes encoding lysosomal proteins as well as ATG proteins (namely the CLEAR network) [74]. The activity of TFEB is strictly dependent on its phosphorylation at Ser211, which is the docking site for the chaperone 14-3-3, responsible for the sequestration of TFEB in the cytosol, preventing its nuclear translocation [77]. The main kinases responsible for TFEB phosphorylation are mTORC1 [78] and the extracellular signal-regulated kinase 2 (ERK2/MAPK1) [79]. In the presence of nutrients, small recombination activating (RAG) GTPases are active and recruit mTORC1 onto the lysosomal membrane, promoting its activation [80]. Upon nutrient deprivation or lysosomal stress, mTORC1 is released from the lysosomal membrane and becomes inactive. These events also induce $\mathrm{Ca}^{2+}$ release from lysosomes through the $\mathrm{Ca}^{2+}$ channel mucolipin 1 (MCOLN1) [81]. The increase in cytosolic $\mathrm{Ca}^{2+}$ concentration activates the phosphatase calcineurin, which dephosphorylates TFEB and promotes its nuclear translocation [81].

\section{Targeting of lysosomal proteins}

After transcription, lysosomal enzymes are co-translationally translocated into the ER membrane or ER lumen, and subsequently processed in the Golgi apparatus before being sorted to reach lysosomes. Most of the soluble lysosomal enzymes acquire high-Man- or hybrid-type $N$-glycans that are characterized by the presence of Man-6-phosphate residues at distinct positions of the oligosaccharide branches [82]. The Man-6-phosphate tags are recognized by two types of specific Man-6-phosphate receptors (M6PRs) in the TGN (Fig. 1) [83]. M6PR-enzyme complexes are transported to EEs through clathrin-coated vesicles before reaching lysosomes. In the EEs, the increased acidity induces the release of the enzymes from M6PRs, which are then recycled back to the
Golgi apparatus (Fig. 1). Interestingly, a different transport mechanism mediated by the lysosomal integral membrane protein 2 (LIMP2/SCARB2) has been identified for the lysosomal enzyme $\beta$-glucocerebrosidase, which is responsible for the hydrolysis of the simplest GSL at its glycosidic bond, i.e. glucosylceramide, in Glc and ceramide, a deficiency being the cause for the lysosomal storage disorder Gaucher's disease [84]. Other LMPs, such as LAMP1 and LAMP2 are also not modified with Man-6-phosphate; their sorting depends on specific signal sequences that are mainly located in their cytosolic tails and/or transmembrane domains $[5,85,86]$.

\section{Lysosomes have numerous functions in cells}

The substrates to be catabolized can reach the lysosomes through two main pathways: endocytosis and autophagy. Although for a long time lysosomes have been considered the final destination for vesicular degradative pathways, it is now clear that they are also crucial regulators of cell homeostasis [87]. Lysosomes are involved in the repair of the plasma membrane through a mechanism involving $\mathrm{Ca}^{2+}$-mediated fusion $[88,89]$. Another important process is lysosomal exocytosis that induces the release of the soluble lysosomal enzymes in the extracellular milieu, while enzymes anchored into the lysosomal membrane become components of the plasma membrane. In particular, the enzymes involved in the catabolism of sphingolipids act directly at the cell surface and fine tune specific pattern of these lipids in the plasma membrane [90, 91]. Lysosomes are also considered $\mathrm{Ca}^{2+}$ storage organelles; the concentration of this cation in their lumen is similar to that found associated with the $\mathrm{Ca}^{2+}$ storage organelles belonging to the ER [92]. $\mathrm{Ca}^{2+}$ is important to regulate different cellular processes, including trafficking, recycling and fusion.

Lysosomes also play a crucial role in cholesterol homeostasis. Cholesterol is an essential structural component of cellular membranes, and the majority of this lipid, i.e., $80 \%$ of its total cellular amount, is found in the plasma membrane where it constitutes about $40 \%$ of the total lipids [92]. Cholesterol is de novo synthesized in the ER, although an important amount can also derive from lowdensity lipoproteins (LDLs) via receptor-mediated endocytosis. In lysosomes, the action of acid lipases liberates non-esterified cholesterol from LDLs [93]. Cholesterol is then transported from lysosomes to other cellular compartments, such as Golgi apparatus, plasma membrane and ER, via two specific cholesterol-binding proteins, NiemannPick C1 (NPC1) and NPC2 [94].

Another interesting process is lysosomal-mediated cell death that occurs upon lysosomal membrane permeabilization followed by the release of hydrolytic enzymes into the cytosol [95]. In particular, the enzymes active at neutral $\mathrm{pH}$, such as cathepsins $\mathrm{B}, \mathrm{D}$ and $\mathrm{L}$, are able to activate 
apoptotic effectors like mitochondrial proteins and/or cytosolic caspases. The features of lysosomal-mediated cell death, which can be necrotic, apoptotic or apoptosislike, depend on the extent of the leakage and the cellular conditions.

Altogether, lysosomes are involved in numerous cellular processes and alterations in their functions have severe consequences on cellular homeostasis, which in turn lead to the onset of severe pathologies including hereditary lysosomal storage disorders.

\section{Glycans and endocytosis}

\section{The different types of endocytosis}

It was Christian De Duve in 1963, who first employed the term 'endocytosis' to describe the cellular uptake processes of macromolecules or fluids from the extracellular space into the cytoplasm [96]. Endocytic vesicles, which are generated from plasma membrane invaginations by budding, transport the ingested material to different intracellular compartments: LEs and lysosomes for degradation, REs for recycling back to the plasma membrane, or many other destinations in the cell such as the Golgi apparatus. At first glance, the size of the initial membrane invagination enables a classification into different endocytic pathways. The internalization of either large particles (such as bacteria, cell debris, or even intact cells) or large volumes of the extracellular bulk phase (relative to the cell volume) are tightly regulated processes called phagocytosis and macropinocytosis, respectively (reviewed in [97-99]). Smaller cargo can be internalized by a plethora of microscale endocytic pathways, which can operate concurrently at the plasma membrane [100]. Amongst them, clathrin-mediated endocytosis (CME) is the most studied and probably the best understood entry route into the cell (reviewed in [101-103]). In addition to $\mathrm{CME}$, cells use a broad variety of alternative, heterogeneous entry routes, roughly classified as clathrin-independent endocytosis (CIE) pathways (reviewed in [104-106]). In contrast to CME, in which each cargo receptor has cytoplasmic sorting motifs leading to the assembly of a well-defined endocytic machinery that generates the clathrin coat, CIE deals with the internalization of various molecules, ranging from glycosphingolipids and GPI-anchored proteins to transmembrane proteins that all lack cytoplasmic domains and consequently also a cytoplasmic sorting motif. Even if each of the CIE pathways has several unique components, many of them share common features, such as association to lipid rafts, implication of cholesterol, actin polymerization and possibly glycosylation.

Many decades of research have shown that endocytosis extends far beyond the mere uptake of material from the extracellular space or the cell surface; it rather interconnects and regulates a multitude of cellular activities, including nutrient uptake, cell signaling, cell migration, cell polarity, antigen presentation and mitosis [107].

\section{The role of protein glycosylation in receptor-mediated endocytosis}

The importance of post-translational modifications, such as phosphorylation or ubiquitylation, for receptor-mediated endocytosis is well-recognized (reviewed in [108, 109]). The pioneering work of Ashwell's laboratory led to the purification of the first endocytic glycan receptor of vertebrates, called the hepatic asialoglycoprotein receptor, and also started the novel research area of mammalian glycan receptors [110-112]. Currently, the number of publications reporting that glycosylation influences the association of receptors with highly specific plasma membrane domains is steadily increasing. A few of these publications are highlighted in detail below.

Kohno and co-workers analyzed the glycosylation pattern of the sphingosine-1-phosphate (Sph-1-P) receptor endothelial differentiation gene-1 product (EDG1) and the influence of glycosylation on its internalization. Former studies had shown that in response to Sph-1-P binding, EDG1 triggers diverse signaling pathways through downstream signaling molecules, such as $\mathrm{Ca}^{2+}$ and mitogen-activated protein (MAP) kinases, by activating heterotrimeric G-proteins. EDG1 is glycosylated at its extracellular domain and one glycosylation site has been identified at Asn30. Although there was no difference in the ligand binding ability and ligand-induced MAP kinase activation between the wildtype and the non-glycosylated mutant Asn30Asp-EDG1, Asn30Asp-EDG1 was much less responsive to ligandinduced internalization. Moreover, in contrast to the wildtype receptor, Asn30Asp-EDG1 was no more associated with the CIE organelles called caveolae, but dispersed broadly in membrane fractions separated by sucrose density gradient centrifugation, suggesting that microdomain localization and internalization of $\mathrm{N}$-glycosylated EDG1 might be connected [113].

Min and colleagues used the $\mathrm{G}$ protein-coupled dopamine D2 and D3 receptors, which are glycosylated at their extracellular domains, as experimental model to study the impact of glycosylation on receptor functions including cell surface expression, signaling, and internalization through specific plasma membrane domains. The results showed that the glycosylation on the $\mathrm{N}$-terminus mediates the internalization of D2 and D3 receptors through caveolae and clathrin-coated pits, respectively, by regulating receptor interactions with caveolin-1 and clathrin [114].

Finally, Altschuler and co-workers observed that CME of the type I transmembrane protein mucin 1 (MUC1) is 
influenced by its glycosylation state. In particular, by comparing the internalization of various glycosylated forms of MUC1 in wild-type and glycosylation-deficient cells, they showed that the initial rate of endocytosis of the underglycosylated MUC1 was stimulated twofold in comparison with normally glycosylated MUC1, while trafficking to lysosomes remained unaffected [115].

Altogether, these examples highlight that glycosylation of specific plasma membrane proteins plays an important regulatory role in their dynamics during endocytosis.

\section{Lectin-glycolipid interactions induce membrane curvature leading to tubular membrane invaginations}

Glycans can act as ligands/receptors for glycan-binding proteins called lectins. Lectins and glycans play crucial roles in multiple physiological and pathological processes. For instance, lectin-glycan interactions are involved in the regulation of cell-surface receptors [116], immune cell migration [117], recognition of pathogens [118], pathogen infection [119]

Table 1 Examples of lectin-glycan interactions in endocytosis. The lectin, the lectin-expressing cell type, and the corresponding glycan interaction partner(s) are indicated

\begin{tabular}{|c|c|c|c|}
\hline Lectin & Cell type/organism & Glycan/receptor & References \\
\hline \multicolumn{4}{|l|}{ C-type lectins } \\
\hline Asialoglycoprotein receptor (ASGR) & Mainly hepatocytes & $\begin{array}{l}\text { Desialylated glycoproteins that con- } \\
\text { tainterminal Gal or GalNAc residues } \\
\text { on theirN-linked glycans, and also } \\
\text { sialylatedglycoproteins with terminal } \\
\text { Sia } 2 \text { 2,6GalNAcand Sia } 2,6 \mathrm{Gal}\end{array}$ & Reviewed in $[265,266]$ \\
\hline CD209/DC-SIGN & Human myeloid dendritic cells & $\begin{array}{l}\text { Branched D-Man and L-Fuc motifscom- } \\
\text { mon on pathogen surfaces; e.g.,mannan, } \\
\text { Lex and Ley }\end{array}$ & Reviewed in [267] \\
\hline Langerin (CD207) & Mainly Langerhans cells & $\begin{array}{l}\text { Man-rich } N \text {-glycans on proteins;e.g., } \\
\text { HIV-1 gp120 envelope protein }\end{array}$ & [268] \\
\hline $\begin{array}{l}\text { Man-binding lectin } \\
\text { (MBL2) }\end{array}$ & Mainly hepatocytes & Man-rich $N$-glycans & [269] \\
\hline \multicolumn{4}{|l|}{$\begin{array}{l}\text { I-type lectins (they bind to non-reduc- } \\
\text { ing terminal sialic acids) }\end{array}$} \\
\hline $\begin{array}{l}\text { Sialic acid binding Ig like lectin } 1 \\
\text { (SIGLEC1/CD169) }\end{array}$ & Macrophages & e.g., HIV-1 gp120 envelope protein & {$[270]$} \\
\hline CD22 & B cells & $\begin{array}{l}\text { Sialoside ligands on the surface of both } \\
\text { the same cell and adjacent cells }\end{array}$ & {$[271]$} \\
\hline \multicolumn{4}{|l|}{$\begin{array}{l}\text { Galectins (they bind to } \beta \text {-galactoside- } \\
\text { containing glycans) }\end{array}$} \\
\hline LGALS1 & e.g. T cells & e.g., PTPRC/CD45 & {$[272]$} \\
\hline LGALS3 & e.g. fibroblasts & e.g., CD44 or glycosphingolipids & [148] \\
\hline \multicolumn{4}{|l|}{ Plant lectins/toxins } \\
\hline Ricin (R-type lectin) & Ricinus communis & $\begin{array}{l}\text { Terminal } \beta \text {-linked Gal- or GalNAc-con- } \\
\text { taining glycans }\end{array}$ & Reviewed in [273] \\
\hline Gs I-A4 & $\begin{array}{l}\text { Griffonia (Bandeirea) simplici- } \\
\text { folia }\end{array}$ & $\begin{array}{l}\text { Terminal } \alpha \text {-linked GalNAc residues, } \\
\text { including the Tn antigen }\end{array}$ & {$[274]$} \\
\hline \multicolumn{4}{|l|}{ Bacterial lectins/toxins } \\
\hline StxB & $\begin{array}{l}\text { Shigella dysenteriae and Escheri- } \\
\text { chia coli }\end{array}$ & Mainly Gb3 & [136] \\
\hline Cholera toxin & Vibrio cholerae & Ganglioside GM1, LeX on proteins & {$[275]$} \\
\hline LecA & Pseudomonas aeruginosa & e.g., Gb3 & [142] \\
\hline RSL & Ralstonia solanacearum & e.g., human histo-blood group antigens & [132] \\
\hline \multicolumn{4}{|l|}{ Viral lectins } \\
\hline VP1 & Simian virus 40 & Ganglioside GM1 & {$[140]$} \\
\hline VP1 & Norovirus GII.4 & $\begin{array}{l}\text { ABH histo-blood group glycans on glyco- } \\
\text { proteins and GSLs }\end{array}$ & {$[141]$} \\
\hline
\end{tabular}


and in many other areas of biology and medicine. Hereby, either membrane-anchored or soluble lectins are responsible of decoding glycan-containing information. Table 1 depicts examples of lectin-glycan interactions that are implicated in diverse endocytosis pathways. The following paragraphs focus on the interactions of lectins with GSLs, which can impose various effects on plasma membrane organization and dynamics (reviewed in [120,121]). In addition to cellular studies, the use of synthetic membrane systems, such as giant unilamellar vesicles or supported lipid bilayers, has contributed substantially to the understanding of the mechanistic details underlying lectin-GSL interactions (reviewed in $[122,123]$ ).

GSLs are mainly found in the extracellular leaflet of the plasma membrane. Their ceramide backbone is embedded in the lipophilic part of the membrane while the carbohydrate moieties are exposed to the extracellular space. The common view is that GSLs tend to associate with each other [124] and are enriched in lipid rafts, where they interact with cholesterol and sphingomyelin $[125,126]$. Nevertheless, variations in the fatty acyl chain of the ceramide backbone, e.g. in length or saturation level, can affect the partitioning and orientation of GSLs in plasma membrane domains [127]. This, in turn, can influence the exposure of the carbohydrate chain rendering it partially inaccessible for binding to ligands [128, 129].

Several lectins and toxins with a subunit acting as lectin, induce membrane curvature by binding to glycolipids in cells or synthetic membrane systems, leading to tubular membrane invaginations [130-135]. For instance, the homo-pentameric B-subunit of Shiga toxin (StxB), which is produced by Shigella dysenteriae and enterohaemorrhagic Escherichia coli strains, specifically recognizes the carbohydrate moieties of the GSL globotriaosylceramide (Gb3, also known as CD77 or the $\mathrm{P}^{\mathrm{k}}$ blood group antigen). StxB can recruit up to $15 \mathrm{~Gb} 3$ molecules underneath its pentameric structure (reviewed in [136]). This multivalent binding leads to Gb3 clustering and local membrane reorganization, resulting in a small increment of negative membrane curvature $[137,138]$. Subsequent membrane-mediated clustering of several StxB molecules creates a tubular plasma membrane invagination that paves the way of StxB into the cell [133, 134]. The molecular mechanism to generate membrane curvature and tubular invaginations is not yet fully understood, but it seems to require the multiplicity and specific architecture of GSL-binding sites (Fig. 3). In order to study the impact of these two crucial parameters on the formation of membrane invaginations, distinct carbohydrate-binding sites of diverse lectins have been modified by site-directed mutagenesis [132, 133, 135]. The StxB variant Trp34Ala, in which the Gb3-binding site III was inactivated by classical mutagenesis, only rarely induced membrane tubules in cells and not at all in giant unilamellar vesicles, even when used at high concentrations to ensure efficient binding [134].
A fully novel approach has been chosen for a more detailed mechanistic study on the induction of membrane invaginations. By linking the three subunits from Ralstonia solanacearum lectin (RSL), several monomeric so-called neolectins (neoRSLs) with different valences were designed, which are highly similar in structure to the wild-type lectin [139]. Compared to the unmodified trimeric and hexavalent lectin, already a divalent, monomeric variant was sufficient to induce tubular membrane invaginations in giant unilamellar vesicles by binding to glycolipids with a Fuc-containing glycan. However, a divalent variant with two adjacent carbohydrate-binding sites was able to form membrane invaginations, while divalent proteins with the binding sites further apart did not deform the membrane, even though their binding affinities were fairly similar [139]. Similar observations, i.e. membrane curvature and tubular membrane invaginations that can form without the assistance of an active cellular machinery, have also been made upon the binding of viral particles to GSLs [124, 140, 141]. For instance, the viral capsid of simian virus 40 , which is composed of 72 VP1 pentamers, each one resembling the 3D-structure of the pentameric B-subunits of cholera or Shiga toxin, binds to the ganglioside GM1 promoting lipid compaction and membrane invaginations [140]. The bacterium Pseudomonas aeruginosa is an excellent example to highlight that also bacteria rely on lectin-induced GSL clustering as a strategy for host cell invasion. The interactions of the tetrameric $P$. aeruginosa lectin LecA with $\mathrm{Gb} 3$, its binding partner on host cell plasma membranes, trigger the cellular uptake of the bacterium into epithelial cells via the so-called lipid zipper mechanism [142].

In summary, even if the initial forces driving the membrane curvature might differ between several lectins and toxins with lectin properties, both viruses and bacteria exploit lectin-induced GSL clustering for cellular uptake and probably also for signaling [143, 144]. In addition to exogenous proteins such as bacterial toxins and viruses, tissue lectins are known to act in a similar manner.

\section{Galectins and glycans regulate endocytic processes}

Galectins are a family of lectins that bind $\beta$-galactosides through a structural $\beta$-sandwich-fold domain ([145]; for a collection of reviews covering the broad range of the field, please see two special dedicated issues of Trends in Glycosciences and Glycotechnology [146, 147]). Galectins have numerous intracellular functions, and after non-classical secretion, they also have extracellular effects and are also involved in endocytosis [148-150]. Two rather controversial findings on the role of glycosylation and galectins in CIE have been reported. 'Galectin lattice', a large (crosslinked) interaction network brought together by galectins, was reported to sequester cargo molecules (e.g. several 

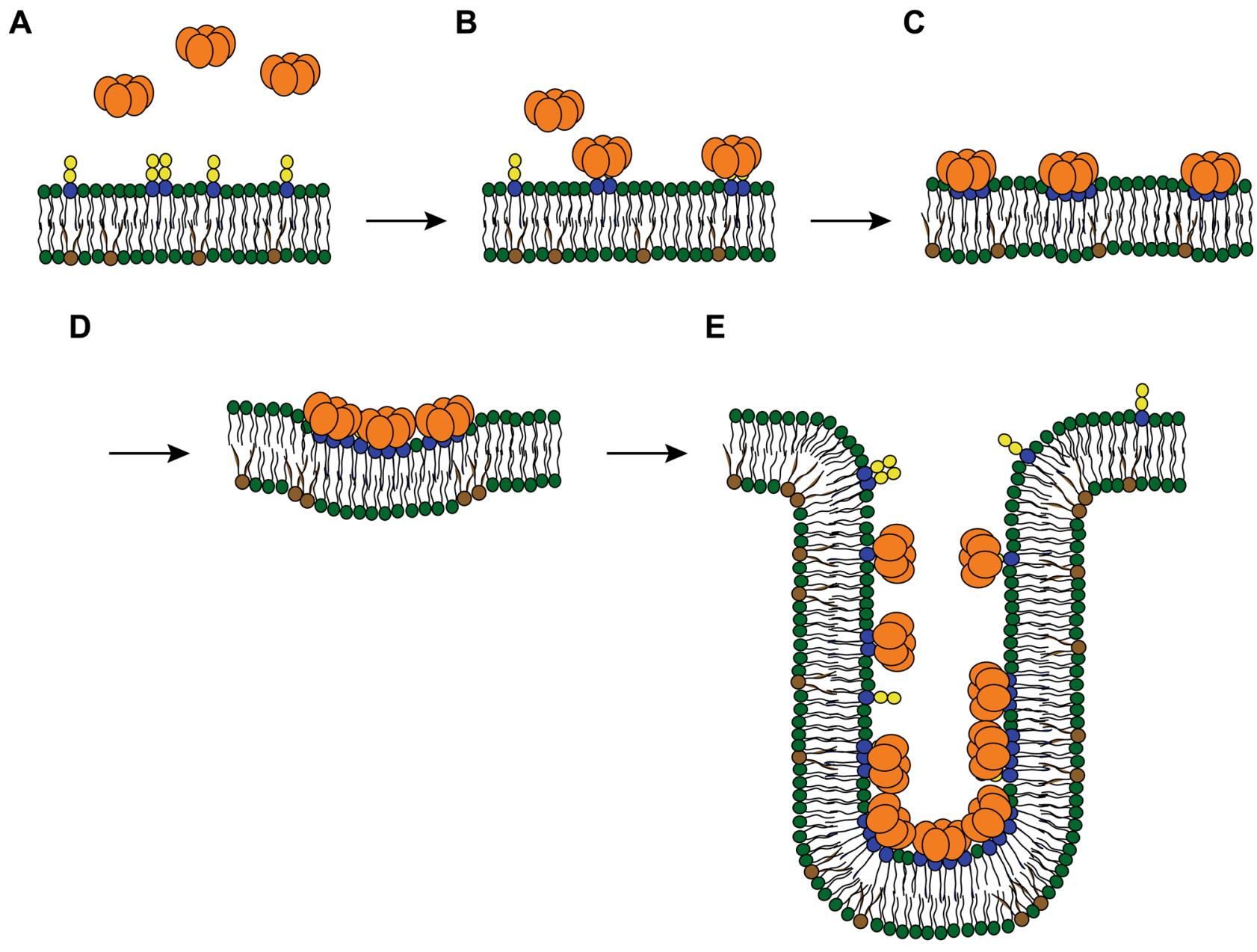

Fig. 3 StxB induces tubular membrane invaginations. A The B-subunit of Shiga toxin ( $\mathrm{StxB}$, orange color) is recruited by the glycosphingolipid Gb3 (carbohydrates are colored in blue and yellow) onto the extracellular membrane leaflet of the plasma membrane. Initially, the pentameric StxB binds to individual Gb3 molecules $\mathbf{B}$ and subsequently, the StxB pentamers are able to cluster up to $15 \mathrm{~Gb} 3$ molecules, lead-

growth factor receptors) at the cell surface, thus inhibiting their cellular uptake [116, 151, 152]. Interestingly, a significant compaction of the LGALS1's carbohydrate recognition domains (CRDs) upon ligand binding, which affects LGALS1 overall structure and increases the stability of the homodimers [153], is probably underlying the mechanism leading to the organization of rigid aggregates [154, 155]. On the contrary, galectin-3 (LGALS3/Gal-3), probably in its pentameric form, was reported to drive the internalization of CD44 in conjunction with GSLs, by bending the plasma membrane in a similar manner as reported for several bacterial toxins [148]. However, these apparently controversial findings, i.e., inhibitory versus stimulatory roles of a galectin, can be reconciled with each other, within the same cell line [150]. That is, the initial galectin-glycan interactions can stimulate CIE while an increasing number of galectin-glycan ing to increased affinity/avidity of interactions. This event leads to a small local negative membrane curvature $\mathbf{C}$. Further $\mathrm{Gb3}$ clustering and membrane reorganization processes $\mathbf{D}$ trigger the formation of narrow tubular membrane invaginations $\mathbf{E}$. Lipids in green and brown color represent different phospholipids with saturated and unsaturated fatty acyl chains, respectively

interactions leads to the assembly of a galectin lattice, which inhibits endocytosis. In light of recent findings, other functional oligomeric states of LGALS3 than pentamers, may exist via the dynamic self-association of its intrinsically disordered N-terminal domain [156]. In a very recent study, Farhadi and colleagues, using engineered LGALS3 constructs (from dimers to hexamers) based on $\alpha$-helical coiledcoil scaffolds, confirmed that glycan-binding properties, clustering and extracellular signaling activities of LGALS3 depend on architecture and valency, extending previous work with engineered LGALS3 [157-159]. The authors of this study also highlighted that the relatively large integral membrane glycoprotein protein tyrosine phosphatase receptor type C (PTPRC/CD45) (in contrast to smaller glycoproteins such as $\mathrm{CD} 7$ ) regulates membrane glycan clustering and cell death signaling activities of synthetic LGALS3 
oligomers [157]. Thus, parameters like the glycosylation pattern, galectin secretion, valency and quaternary structure have a major impact on galectin-glycan interactions, which in turn modulate the fate of diverse cargo proteins $[150,157]$.

In conclusion, the interactions between glycans and lectins appear to be a versatile strategy that cells employ not only to regulate endocytosis, but also to modulate intracellular signaling pathways, thus regulating cell migration, proliferation, apoptosis and other cellular processes.

\section{Glycans and autophagy}

\section{ATG9A is an N-glycosylated transmembrane protein}

ATG9A has been recognized as an essential protein for autophagosome formation for a long time (Fig. 2), but its molecular mechanisms were only recently recovered. ATG9A, unlike all the other core ATG proteins, is an integral membrane protein, which traffics between the TGN and endosomes [160]. It has four transmembrane segments and two helices that enter and exit the membrane on the cytosolic side, and both the C- and N-termini are cytosolic [161-163]. Vesicles containing ATG9A are required for phagophore assembly [164], and traffic to phagophore assembly sites from either the REs or TGN [165-168]. Recent results show that ATG9A vesicles function as seeds for phagophore biogenesis [169]. The cryo-electron microscopy structures of human ATG9A and fission yeast Atg9 were recently solved. The structure is a homotrimer that has a unique fold and an internal network of branched cavities [161-163]. Notably, the cavities form a path between the two leaflets of the lipid bilayer; ATG9A functions as a flippase that facilitates lipid translocation from the cytoplasmic to luminal leaflet of ATG9Apositive membranes, thereby enabling the elongation of nascent phagophores [162,163]. Association of ATG9A with ATG2 proteins (ATG2A and ATG2B), is crucial for phagophore biogenesis [170]. ATG2A and ATG2B are rod-shaped lipid transfer proteins [171-174]. The current view is that ATG2 proteins transport lipids from the ER to the cytoplasmic leaflet of the growing phagophore membrane, and ATG9A then distributes the lipids to the luminal leaflet in order to facilitate phagophore elongation $[175,176]$. ATG9A is glycosylated with a complex-type $\mathrm{N}$-glycan at Asn99 between the first and second transmembrane segments; Asn99 is the only one of the potential $\mathrm{N}$-glycosylation sites in ATG9A that is used [160, 177]. The presence of ATG9A is a possible explanation for the early observations of Yamamoto and colleagues, showing that the growing edges of phagophores have binding sites for concanavalin A, wheat germ agglutinin and Ricinus communis agglutinin 120, which bind Man, GlcNAc and sialic acid, and terminal $\beta$-Gal residues, respectively [178]. However, the role of the ATG9A $N$-glycan in its trafficking and function at the phagophore remains totally unexplored.

\section{Glycolipids and GIcNAc-modified proteins in autophagy}

In addition to the transmembrane glycoprotein ATG9A, also glycolipids have roles in phagophore biogenesis. The ganglioside Gd3 colocalizes with LC3 proteins, suggesting it is present in autophagosomal membranes. Perturbations in Gd3 biosynthesis inhibit autophagosome biogenesis [179]. This glycolipid may contribute to the curvature and/ or fluidity of the membrane, which are likely to modulate membrane dynamics during autophagosome biogenesis.

As mentioned above, attachment of GlcNAc to the hydroxyl group of serine or threonine residues of proteins is a special type of glycosylation taking place in the cytoplasm $[57,180]$. $O$-GlcNAc transferase adds this sugar moiety while $O$-GlcNAcase cleaves it, and the modification responds to a variety of environmental conditions and acts as a stress signal in many intracellular processes including autophagy [180]. Like autophagy, $O$-GlcNAcylation is regulated by nutrient availability. The ULK1 kinase, which is central in autophagy induction, is modified by $O$-Glc $N A c$ at Thr754 during glucose starvation, and this modification is required for the activation of PIK3C 3 and initiation of autophagosome formation [181] (Fig. 2). The central autophagy protein BECN1, which is part of the phosphatidylinositol 3-kinase complex complex I, was also shown to be modified by $O$-GlcNAc, but in this case the modification was proposed to inhibit autophagy. Further, the levels of $O$-GlcNAcylated BECN1 were observed to be increased in the hearts of diabetic animals [182]. The authors of this study suggested that increased $O$-GlcNAcylation levels in diabetic heart may contribute to the abnormal autophagic response to Glc deprivation. The fusion of autophagosomes with endosomes and lysosomes is regulated by SNAREproteins. One component of the SNAREs that regulate this fusion is synaptosome associated protein 29 (SNAP29), which is $O$-GlcNAcylated at four residues: Ser2, Ser61, Thr130 and Ser153. Preventing this modification in all four residues by point mutations enhances the formation of the SNAP29-containing SNARE complexes, thus increasing the fusion of autophagosomes with LEs and lysosomes [183]. Consistently, $O$-GlcNAcylation of SNAP29 is reduced during starvation, which promotes autophagosome maturation. Thus, $O$-GlcNAcylation of SNAP29 regulates autophagic flux according to the cellular nutrient status. 


\section{Regulation of autophagy by extracellular glycoproteins and proteoglycans}

Interactions of cell-surface receptors and extracellular glycoprotein ligands regulate intracellular pathways, including autophagy. Plasma membrane receptors bind soluble ligands as well as molecules attached to the extracellular matrix. Many soluble extracellular glycoprotein ligands such as decorin (DCN), thrombospondin 1 (THBS1), biglycan (BGN), endostatin (COL18A1), collagen VI and plasminogen kringle 5 activate autophagy in cancer cells, leading to inhibition of angiogenesis and tumor growth, while others such as laminin $\alpha 2$ chain (LAMA2) and lumican (LUM) are anti-autophagic [184-186]. Extracellular matrix-associated glycoprotein ligands mostly appear to repress autophagy. Attachment of cells to the basement membrane tends to restrict autophagic activity at a basal level, while cells detached from the basement membrane activate autophagy as a survival mechanism [187, 188]. Many plant lectins have shown potential as cancer treatments through autophagy modulation. As an example, concanavalin A treatment induces autophagy and cell death in U87 glioblastoma and HeLa epitheloid cervix carcinoma cells $[189,190]$. The signals from extracellular glycoproteins and proteoglycans are thought to converge with common core autophagy machinery via their cell-surface receptors and autophagy-activating signalling pathways [186]. However, the detailed signalling routes that extracellular glycoproteins and plant lectins use to modulate autophagy have not been fully characterized (reviewed in [186, 191]).

\section{Glycans and protein quality control}

$\mathrm{N}$-Glycans as signal are an elegant solution for the quality control and transport of a glycoprotein. As noted above, all $\mathrm{N}$-glycans initially have the $\mathrm{Glc}_{3} \mathrm{Mac}_{9} \mathrm{GlcNAc}_{2}$ structure that is trimmed after quality control and then reshaped in the Golgi. Thus, $\mathrm{N}$-glycans carry out three main tasks in the same way for all glycoproteins. First, they provide the assistance in correctly folding the proteins in the ER by being the docking site of the lectin chaperones calnexin (CANX) and calreticulin (CALR). Second, they label misfolded proteins for ER-associated degradation (ERAD) by a complex containing an F-box protein with lectin activity. Third, they are the molecular equivalent of a postal code for routing glycoproteins from the ER toward the Golgi and beyond by lectin cargo shuttles such as lectin Man binding 1 (LMAN1/ERGIC53), lectin Man binding 1 like (LMAN1L/ ERGL), lectin Man binding 2 (LMAN2/VIP36) and lectin Man binding 2 like (LMAN2L/VIPL) [53, 192-199]. Within the lumen of the ER, Glc residues in $N$-glycans can be recognized by the lectin chaperones CALR and CANX, and this binding is not outcompeted by soluble Glc since Glc is absent at this location. As Gesner and Ginsburg noted in 1964, a recognition signal based on Glc would not work on the cell surface [200]. Cycles of deglucosylation/ reglucosylation during chaperone-guided folding in the ER lumen ensure sufficient encounter of glycoproteins with the quality-control elements. Interestingly, a plethora of further functions in cancer biology is being unraveled for these ER chaperones [201].

Of particular relevance to illustrate variability, the CRDs of the lectins act in concert with other sections of the CRD, with other domains (in modular lectins) or with other subunits when lectins are part of a complex. This principle of modularity is known for the chaperones and their interaction with ER folding factors such as ERp57 (protein disulfide isomerase family member 3, PDIA3) via the P-domain [202]. Instead of different domains within a lectin working together, the CRD of LMAN1 pairs with a different protein, i.e. MCFD2, to interact with the cargo, possibly via its glycan and protein parts [203, 204]. Complex formation through bifunctional interaction also applies to F-box proteins to assemble the S-phase kinase-associated protein 1 (SKP1) - cullin-1 (CUL1) -F-box (SCF) E3 ubiquitin ligase complexes, a key effector in ERAD. The first F-box protein identified as lectin was the F-box protein recognizing sugar chain 1 (FBX02/ FBS1), which displays specificity for the (Glc NAc) $)_{2}$ stem in the $\mathrm{N}$-glycan core and gets access to it in unfolded glycoproteins $[198,205,206]$. In addition to ubiquitination as a mode to label products of inadequate quality for ER-associated degradation, distinct SCF complexes can also trace glycoproteins that have already reached other compartments along the secretory pathway. For example, FBX027/FBS3 is the sensor part of the SCF complex that adds ubiquitin to glycoproteins that are exposed to the cytoplasm upon lysosomal membrane damage, to recruit the autophagy receptors such as sequestosome 1 (SQSTM1/p62) and to promote the autophagic turnover of the damaged organelle [198, 207]. The glycans of LAMP2 are the biorelevant binding partners of FBX027 in the context of lysosome damage [208]. Notably, the glycans of LAMP proteins are also recognized by another family of $\beta$-sandwich-type lectins, known as Gal-binding lectins or galectins (see below) [209, 210].

Homeostasis within the ER protein-folding factory and thus the flux of mature soluble and membrane (glyco)proteins is guaranteed by the unfolded protein response (UPR) [211-213]. Accumulation of misfolded and/or unfolded (glyco)proteins in the ER triggers a safeguard mechanism that is under the control of two UPR-specific transcription factors, X-box binding protein 1 (XBP1), and/or the activating transcription factor 6 (ATF6), as well as ATF4, another 
transcription factor. Those lead to the enhanced expression of the components of ER protein-folding machinery, including the ER-localized lectins, which leads to the upregulation of the chaperoning activity, and permits to restore the ER-based quality control. UPR also induces autophagy, in particular ER-phagy, to alleviate ER expansion induced by ER stress and also acts as an alternative disposal pathway for misfolded proteins [214]. Interestingly, the XBP1-triggered shifts in the $\mathrm{N}$-glycan profile in cell line models such as HEK293 and HeLa, suggests the existence of a connection between the intracellular stress response and extracellular $N$-glycan functions [215, 216], but the physiological relevance of this phenomenon remains to be uncovered.

Overall, ER-resident lectins participate in the ER quality control and in routing glycoproteins to the Golgi and beyond, by associating with trimmed $\mathrm{N}$-glycans and using more than one binding domain. The bifunctionality in binding is generated by either covalent association of the CRD and non-CRD modules within a single lectin, or by noncovalent assembly of a lectin with other proteins [217, 218]. Signaling damage of an endolysosomal compartment by recognizing cytoplasmic exposure of the $N$-glycans of LAMP2 represents a paradigm: galectin-9 (LGALS9/Gal-9) binds to the $N$-acetyllactosamine repeats in the $N$-glycan attached to Asn175 [210]. Of note, poly- $N$-acetyllactosamine stretches in $N$-glycans (preferably in $\beta 1,6$-branches), mucin-type cores $2 / 4 O$-glycans and keratan sulfate, are also high-affinity binders for (LGALS1/Gal-1) and galectin-3 (LGALS3/Gal3) $[219,220]$. That is, galectins are a candidate for announcing that something is wrong, after having detected mature $\mathrm{N}$-glycans at an inappropriate place, i.e., reoriented or accessible in the cytoplasm [221-223]. This concept of a signal, a mature $N$-glycan becoming cytoplasmic, and its sensor, a cytoplasmic lectin endowed with bifunctionality, gave an incentive to look at galectin functions more closely.

\section{The roles of glycans in maintaining the integrity of the endolysosomal compartments}

\section{Intracellular damage and galectins}

The hypothesis for a role of glycans in the "establishment of cell-cell contacts and possibly also as mediators of communication between the surface and the interior of the cell" prompted researchers in Rehovot to apply an activity assay for detection of lectins, i.e. the haemagglutination reaction commonly used for testing plant extracts, on nervous tissue [224]. These experiments found a strong lectin activity in the electric organ of the electric eel Electrophorus electricus, as well as in rat, mouse and embryonic chicken tissues [224]. Since the presence of $\beta$-galactosides inhibited this lectin activity, affinity chromatography of tissue extracts on Galpresenting resin yielded to the purification of the first galectin [224]. Further work along this line, and the biochemical analyses of the obtained proteins, revealed conserved amino acid sequences that are responsible for the key interactions with the cognate $\beta$-galactoside residues on glycans. This sequence signature is the common denominator of galectins and highlights the probable diversification of this type of $\beta$-sandwich proteins from an ancestral single gene into a protein family [225-229]. In addition to the sequence signature, the absence of a signal peptide sequence is another unique feature of the vertebrate galectins [227, 230, 231]. Thus, as opposed to the above-mentioned classes of $\beta$-sandwichtype lectins involved in quality control and cargo transport through the secretory pathway, galectins do not enter the ER and the endomembrane system. Their cytoplasmic presence qualifies them for the suggested assignment to control compartment integrity.

To be intracellular sensors and initiators of a protective response, galectins must possess an in-built bifunctionality. Indeed, binding partners of galectins are on the one hand the glycoconjugates, glycoproteins, proteoglycans and glycolipids via their glycans, and on the other hand cytoplasmic and extracellular proteins (LGALS1 and LGALS3 interactors have recently been compiled [229]). The cooperative interplay between two different binding sites establishes the specific pairing between a specific glycan and particular protein so that a galectin can act like a molecular glue, bridging a glycan signal with an effector or modulator element. The prerequisite of serving as a molecular hinge is fulfilled by the three types of vertebrate galectins, i.e., non-covalently associated homodimers (i.e., proto types), linker-connected heterodimers (i.e., tandem-repeat types) and chimera composed by a CRD and an N-terminal tail with collagen-like repeats or other domains (i.e., chimera types) [159] (Fig. 4). For example, the chimera-type LGALS3 is engaged in phagocytic clearance of glycan-presenting apoptotic cells and cellular debris by simultaneously interacting with the glycans on the cargo and the MER proto-oncogene tyrosine kinase (MERTK) on the surface of phagocytic cells [232]. LGAL3 is also engeged in immune regulation via binding to cell surface glycans and the chemokine CXCL12 [233]. Homodimeric (proto-type) galectins such as LGALS1/Gal-1 alternatively mediate cross-linking by homo- and heterotypic interactions. In fact, the in-built "binding promiscuity" has been suggested to explain "the variety of adhesion phenomena by galectin-1" [234]. In contrast to tandem-repeat-type galectins such as galectin-8 (LGALS8/Gal-8) or LGALS9, which possess two different CRDs connected by a linker, the association of two CRDs in proto-type galectins is noncovalent (Fig. 4).

In summary, galectins have the properties for serving as guardians of intracellular organelle integrity, i.e., they are 


\section{Proto type (e.g. LGALS1/Gal-1)}

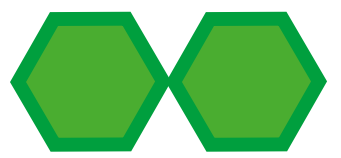

Tandem-repeat type (e.g. LGALS8/Gal-8)

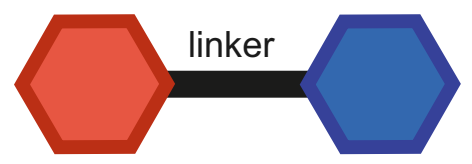

Chimera type (e.g. LGALS3/Gal-3)

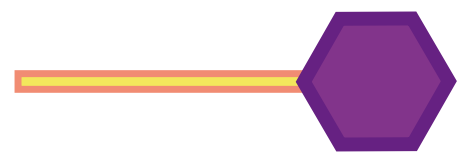

Fig. 4 Schematic illustration of the three types of modular architecture of vertebrate galectins. The hexagon symbolizes the beta-sandwichtype carbohydrate recognition domain (CRD). Non-covalent association to a homodimer and conjugation of two different CRDs (as shown by the color coding) by a linker establish the proto type and tandemrepeat type, respectively. Extension of the canonical CRD by a tail comprising for example collagen-like repeats as in the case of galectin-3 (LGALS3), leads to the chimera type

cytoplasmic and they specifically recognize their cognate glycans on a set of particular intraluminal glycoproteins. Involving more than a single galectin in surveillance of organelle integrity gives versatility to this system.

\section{The role of galectins in membrane damage repair and autophagy}

Early indications for a participation of LGALS3 in membrane integrity surveillance came from its identification as a protein associated to latex bead-containing phagosomes [235]. LGALS3 was also shown to accumulate primarily at the cytosolic face of the limiting membrane of Mycobacterium-containing phagosomes [236, 237]. In fact, this lectin gained the status of a protein marker for vacuolar lysis by invasive pathogens [237, 238]. As a member of a group of antibacterial proteins, guanylate-binding protein 2 (GBP2) is attracted by LGALS3 to vacuoles containing pathogens such as Yersinia [239]. Called a sweet way of sensing danger [240], the physiological relevance of the cytosolic exposure of $N$-glycans upon membrane damage, and their recognition by galectins, become evident when these events were connected with the turnover of the damaged organelle by autophagy [241]. In particular, it was shown that vacuoles ruptured by invading Salmonella recruit chimera-type
LGALS8, which in turn associates with the autophagy receptor calcium binding and coiled-coil domain 2 (CALCOCO2/NDP52) [241]. Binding between these two proteins is principally mediated by the hydrophobic complementarity of the residues 372-380 of CALCOCO2 and those in the C-terminal CRD of the heterodimeric LGALS8 [242, 243]. This type of pairing is also taking place upon escape of TAU protein aggregates from damaged endosomes, to guarantee cell protection [244]. LGALS8 also interacts with the parkin RBR E3 ubiquitin protein ligase (PRKN), which ubiquitinates the group A Streptococcus disrupting the phagosomes and entering the cytoplasm [245]. In contrast, the damage of endocytic compartments caused by $\mathrm{Ca}^{2+}$ phosphate precipitates leads to the LGALS3-mediated recruitment of the autophagy receptor SQSTM1 and subsequent engagement of autophagy for lysosomal turnover of the disrupted organelle [246]. The onset of autophagy triggered by endosomal/ lysosomal damage also involves tripartite motif containing (TRIM) proteins, especially TRIM16, which associate with LGALS3 that has traced the cytosolic presence of mature $N$-glycans [247]. Since the composition of the cell surface glycome has been shown to determine the extent of galectin binding to disrupted endocytic compartments [248], it makes sense that cells possess more than one galectin to initiate an autophagy response to eliminate damaged endocytic and lysosomal organelles.

The physiological significance of the interaction of cytosolicexposed mature $N$-glycans and galectins as bifunctional sensors for intracellular membrane integrity is also underscored by their role in the repair and degradation of the compartments of the endolysosomal system upon damage not caused by invading pathogens. LGALS8 is required for the recognition of damaged endosomes by the autophagy (ATG) machinery, so that they are transported by autophagosomes to lysosomes for degradation by a selective type of autophagy known as lysophagy (Fig. 5) [249]. However, LGALS8 and LGALS9 also cooperate to regulate signaling after lysosomal disruption to inhibit mTORC1 and activate AMPK, which triggers both autophagy and the nuclear translocation of TFEB, which both promotes the de novo biogenesis of new lysosomes to replace the degraded ones, and stimulates autophagy (Fig. 5) [250, 251]. Molecularly, LGALS9 displaces the deubiquitinase ubiquitin specific peptidase 9 X-linked (USP9X) from the mitogen-activated protein kinase kinase kinase 7 (MAP3K7/TAK1)-containing complexes, and promotes K63 ubiquitination and activity of MAP3K7, an upstream kinase and AMPK activator [251].

Importantly, a functional connection between galectin and the membrane repair machinery was discerned with the identification of the interaction between LGALS3 and programmed cell death 6 interacting protein (PDCD6IP/ ALIX), charged multivesicular body protein 4A (CHMP4A) and CHMP4B, which are components of the ESCRT system (Fig. 5) [252]. The docking of LGALS3 onto the damaged 


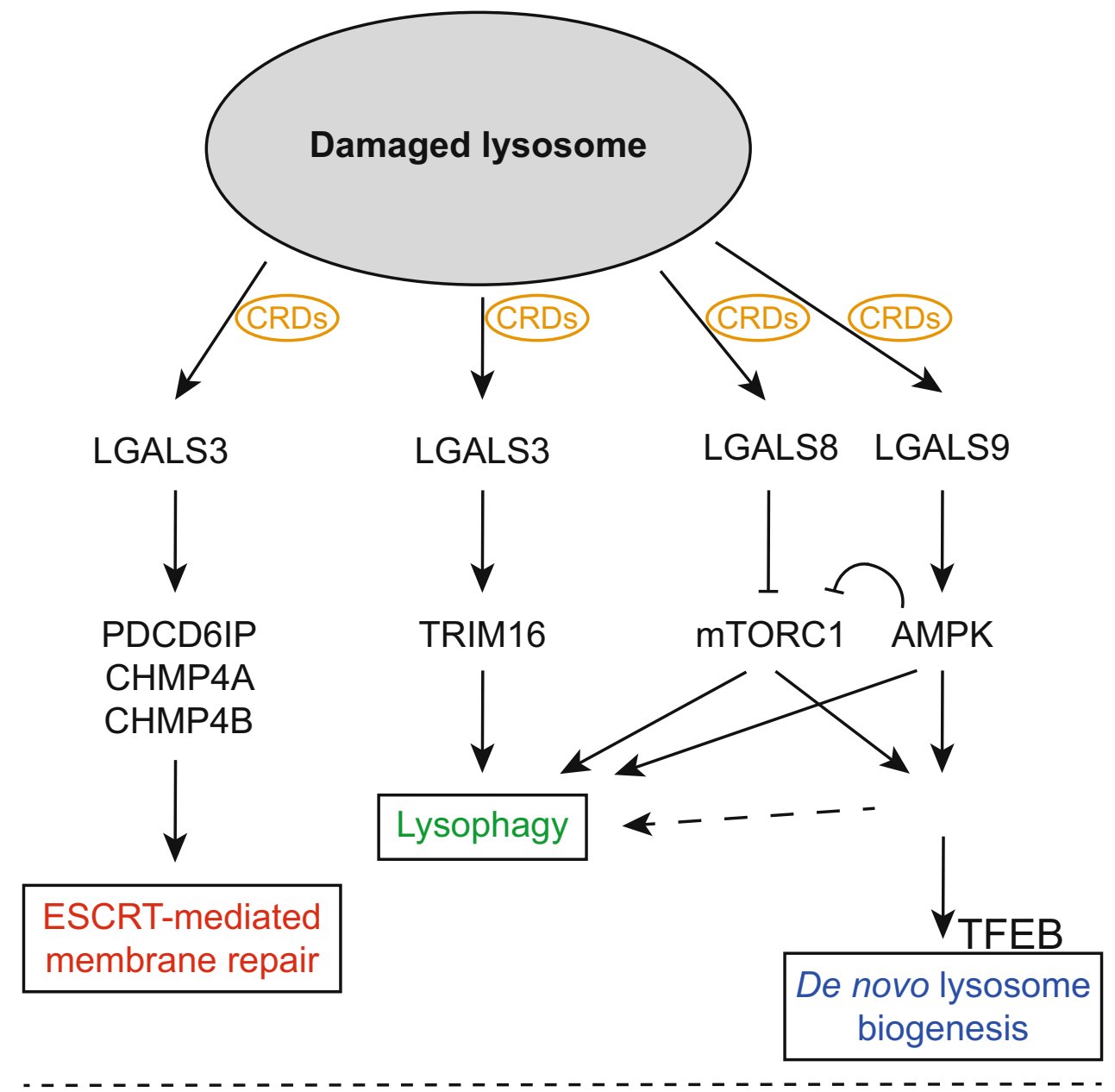

MERIT

Fig. 5 Model illustrating the membrane repair, removal and replacement (MERIT) system. Lysosome membrane damage leads to the cytoplasmic exposure of otherwise not accessible determinants for the cytoplasmic membrane integrity surveillance system. In particular, exposed $\mathrm{N}$-glycans are a signal for danger and locally recruit and probably concentrate galectins (LGALS3, 8, 9), which bind the glycans through their carbohydrate recognition domains (CRDs). The bifunctionality of galectins allows them to engage downstream players of the MERIT system, which coordinates lysosomal membrane repair, lysosome removal and replacement. LGALS3 recruits the endosomal sorting complexes required for transport (ESCRT) components programmed cell death 6 interacting protein (PDCD6IP),

lysosome through binding to the exposed $\mathrm{N}$-glycans, leads to the recruitment of PDCD6IP and promotes its interaction with the charged multivesicular body protein 4C (CHMP4C) [253], a downstream effector of the ESCRT-III subcomplex that has the ability to seal damaged membranes [254]. Structurally, the $N$-terminal tail of LGALS3, a section relevant for the lectin's self-association [255, 256], interacts with the proline-rich region of PDCD6IP [257].

Thus, galectins, due to their dual specificity for glycans and protein effectors, appear to be sensor elements charged multivesicular body protein 4A (CHMP4A) and CHMP4B, and promotes the formation of ESCRT machinery to repair the damaged lysosomal membranes. LGALS3 also cooperates with tripartite motif containing 16 (TRIM16) to guide autophagy initiation machinery to turnover terminally injured lysosomes. Synergistically, LGALS8 inactivates target of rapamycin complex 1 (mTORC1), while LGALS9 activates AMP-activated kinase (AMPK), which further inhibits mTORC1. The mTORC1 inactivation and AMPK activation lead to cell growth arrest, induction of autophagy and transcription factor EB (TFEB) nuclear translocation to replace damaged lysosomes through de novo biogenesis

and nucleation core for a system for lysosomal membrane repair, removal and replacement (MERIT) (Fig. 5) [258]. In particular, LGALS3 detects membrane damage by binding the cognate part of exposed lumenal $\mathrm{N}$-glycans, recruits and organizes ESCRT components at damaged sites on the lysosomes, and facilitates ESCRT-driven repair of the lysosomal membrane (Fig. 5) [253]. At later stages, LGALS3 cooperates with TRIM16 to engage the ATG machinery in the removal of excessively damaged lysosomes through lysophagy [253]. In the absence of 
LGALS3, repair and autophagy are less efficient, whereas TFEB nuclear translocation increases to compensate lysosomal deficiency via de novo lysosomal biogenesis. It remains unclear whether LGALS1, LGALS8 and LGALS9 are multitasking like LGALS3, or whether they are equipping the membrane integrity surveillance system with different types of sensors and/or quality control solutions. Interestingly, the recent discovery of the formation of galectin hybrids via their CRDs may add an additional level of complexity to this regulatory system [259]. Future studies will help deciphering this emerging area of the cell biology of galectins.

\section{Conclusions and perspectives}

Glycans appended to lipids and proteins appear in all the compartments of the secretory and endolysosomal systems, especially the luminal side of their limiting membranes. Our knowledge on the functioning of these systems interconnected by vesicular transport pathways and membrane contact sites has greatly increased through the development of sophisticated cell biological and biochemical tools, such as superresolution microscopy, correlative light-electron microscopy, mass spectrometry-based proteomics and glycoproteomics, and different high-throughput screening methodologies. Although the transport routes to lysosomes have for long been seen as the digestive system of the cell, numerous recent findings have revealed that the endolysosomal compartments have key roles in the regulation of metabolism and immunity, and as signaling platforms that modulate multiple cell and tissue functions. As a result, glycans and their dynamic modifications represent a mechanism to fine-tune some of these functions, as underlined by the known examples in endocytosis and autophagy highlighted in this review. Indeed, turning cryptic signals into actual signals or switching off activity by a deglycosylation step such as the desialylation of ganglioside GD1a to GM1 [260, 261], are being considered efficient regulatory mechanisms for transport and adhesion [262], or cell growth and differentiation, in this case with galectins or sialic acid-binding immunoglobulin-type lectins (siglecs) as readers of the sugar code. Thus, the mechanics of carbohydrate language is being unraveled, and a dictionary for the relationship between the glycan vocabulary and functions is being set up [263]. As recently predicted, "given the tremendous scientific discoveries in the field lying on and beyond the horizon, life for these future glycobiologists will be sweet indeed" [264].

Acknowledgements The authors thank Prof. Luigi Lay (Department of Chemistry, University of Milan, Italy) for his major input in initiating and leading the COST Action CA18103, Innovation with Glycans (INNOGLY): New frontiers from synthesis to new biological targets (https://innogly.eu/). This publication is based upon work in COST Action CA18103, supported by COST (European Cooperation in Science and Technology). W.R. was supported by the German Research Foundation (DFG) under Germany's Excellence Strategy (CIBSS - EXC-2189 and BIOSS - EXC 294) and the Freiburg Institute for Advanced Studies (FRIAS). F.R. was supported by Earth and Life Sciences (ALW) Open Programme (ALWOP.310), Dutch Research Council Domain Science (ENW) KLEIN-1 (OCENW.KLEIN.118) and Netherlands Organisation for Health Research and Development (ZonMW) TOP (91217002) grants. E.L.E was supported by Magnus Ehrnrooth Foundation. We dedicate this review to our co-author Professor Hans-Joachim Gabius, who suddenly passed away in the beginning of August 2021.

Funding Open access funding provided by University of Turku (UTU) including Turku University Central Hospital.

\section{Declarations}

Ethical approval This article does not contain any studies with animals performed by any of the authors.

Conflict of interest The authors declare that they have no conflicts of interest.

Open Access This article is licensed under a Creative Commons Attribution 4.0 International License, which permits use, sharing, adaptation, distribution and reproduction in any medium or format, as long as you give appropriate credit to the original author(s) and the source, provide a link to the Creative Commons licence, and indicate if changes were made. The images or other third party material in this article are included in the article's Creative Commons licence, unless indicated otherwise in a credit line to the material. If material is not included in the article's Creative Commons licence and your intended use is not permitted by statutory regulation or exceeds the permitted use, you will need to obtain permission directly from the copyright holder. To view a copy of this licence, visit http://creativecommons.org/licenses/by/4.0/.

\section{References}

1. Appelmans, F., Wattiaux, R., De Duve, C.: Tissue fractionation studies. 5 . The association of acid phosphatase with a special class of cytoplasmic granules in rat liver. Biochem J. 59, 438-45 (1955)

2. De Duve, C., Pressman, B.C., Gianetto, R., Wattiaux, R., Appelmans, F.: Tissue fractionation studies. 6. Intracellular distribution patterns of enzymes in rat-liver tissue. Biochem J. 60, 604-17 (1995)

3. Ghosh, P., Kornfeld, S.: The GGA proteins: key players in protein sorting at the trans-Golgi network. Eur. J. Cell. Biol. 83, 257-262 (2004)

4. Ghosh, P., Kornfeld, S.: The cytoplasmic tail of the cation-independent mannose 6-phosphate receptor contains four binding sites for AP-1. Arch. Biochem. Biophys. 426, 225-230 (2004)

5. Bonifacino, J.S., Traub, L.M.: Signals for sorting of transmembrane proteins to endosomes and lysosomes. Annu. Rev. Biochem. 72, 395-447 (2003)

6. Luzio, J.P., Hackmann, Y., Dieckmann, N.M., Griffiths, G.M.: The biogenesis of lysosomes and lysosome-related organelles. Cold Spring Harb. Perspect. Biol. 6, a016840 (2014)

7. Pols, M.S., van Meel, E., Oorschot, V., ten Brink, C., Fukuda, M., Swetha, M.G., et al.: hVps41 and VAMP7 function in direct TGN to late endosome transport of lysosomal membrane proteins. Nat. Comm. 4, 1361 (2013)

8. Swetha, M.G., Sriram, V., Krishnan, K.S., Oorschot, V.M., ten Brink, C., Klumperman, J., et al.: Lysosomal membrane protein composition, acidic $\mathrm{pH}$ and sterol content are regulated via a 
light-dependent pathway in metazoan cells. Traffic 12, 10371055 (2011)

9. Braulke, T., Mach, L., Hoflack, B., Glossl, J.: Biosynthesis and endocytosis of lysosomal enzymes in human colon carcinoma SW 1116 cells: impaired internalization of plasma membraneassociated cation-independent mannose 6-phosphate receptor. Arch. Biochem. Biophys. 298, 176-181 (1992)

10. Reggiori, F., Pelham, H.R.B.: A transmembrane ubiquitin ligase required to sort membrane proteins into multivesicular bodies. Nat. Cell. Biol. 4, 117-123 (2002)

11. Reggiori, F., Monastyrska, I., Verheije, M.H., Cali, T., Ulasli, M., Bianchi, S., et al.: Coronaviruses hijack the LC3-I-positive EDEMosomes, ER-derived vesicles exporting short-lived ERAD regulators, for replication. Cell Host Microbe. 7, 500-508 (2010)

12. Fregno, I., Fasana, E., Bergmann, T.J., Raimondi, A., Loi, M., Solda, T, et al.: ER-to-lysosome-associated degradation of proteasome-resistant ATZ polymers occurs via receptormediated vesicular transport. EMBO J. 37, e99259 (2018)

13. Zeigerer, A., Gilleron, J., Bogorad, R.L., Marsico, G., Nonaka, H., Seifert, S., et al.: Rab5 is necessary for the biogenesis of the endolysosomal system in vivo. Nature. 485, 465-470 (2012)

14. Naslavsky, N., Caplan, S.: The enigmatic endosome - sorting the ins and outs of endocytic trafficking. J. Cell Sci. 131, jcs216499 (2018)

15. Rink, J., Ghigo, E., Kalaidzidis, Y., Zerial, M.: Rab conversion as a mechanism of progression from early to late endosomes. Cell. 122, 735-749 (2005)

16. Gary, J.D., Wurmser, A.E., Bonangelino, C.J., Weisman, L.S., Emr, S.D.: Fab1p is essential for PtdIns(3)P 5-kinase activity and the maintenance of vacuolar size and membrane homeostasis. J. Cell Biol. 143, 65-79 (1998)

17. Peden, A.A., Oorschot, V., Hesser, B.A., Austin, C.D., Scheller, R.H., Klumperman, J.: Localization of the AP-3 adaptor complex defines a novel endosomal exit site for lysosomal membrane proteins. J. Cell Biol. 164, 1065-1076 (2004)

18. Yim, W.W., Mizushima, N.: Lysosome biology in autophagy. Cell Discov. 6, 6 (2020)

19. Kaushik, S., Cuervo, A.M.: The coming of age of chaperonemediated autophagy. Nat. Rev. Mol. Cell Biol. 19, 365-381 (2018)

20. Mizushima, N., Komatsu, M.: Autophagy: renovation of cells and tissues. Cell 147, 728-741 (2011)

21. Eskelinen, E.L., Saftig, P.: Autophagy: A lysosomal degradation pathway with a central role in health and disease. Bba-Mol. Cell Res. 1793, 664-673 (2009)

22. Pyo, J.O., Yoo, S.M., Jung, Y.K.: The interplay between autophagy and aging. Diabetes Metab. J. 37, 333-339 (2013)

23. Stead, E.R., Castillo-Quan, J.I., Miguel, V.E.M., Lujan, C., Ketteler, R., Kinghorn, K.J., et al.: Agephagy - adapting autophagy for health during aging. Front. Cell Dev. Biol. 7, 308 (2019)

24. Ichimiya, T., Yamakawa, T., Hirano, T., Yokoyama, Y., Hayashi, Y., Hirayama, D., et al.: Autophagy and autophagy-related diseases: A review. Int. J. Mol. Sci. 21, 8974 (2020)

25. Mizushima, N., Levine, B.: Autophagy in human diseases. N. Engl. J. Med. 383, 1564-1576 (2020)

26. Silva, V.R., Neves, S.P., Santos, L.S., Dias, R.B., Bezerra, D.P.: Challenges and therapeutic opportunities of autophagy in cancer therapy. Cancers (Basel). 12, 3461 (2020)

27. Alvarez-Meythaler, J.G., Garcia-Mayea, Y., Mir, C., Kondoh, H., ME, LL.: Autophagy takes center stage as a possible cancer hallmark. Front. Oncol. 10, 586069 (2020)

28. Poillet-Perez, L., White, E.: Role of tumor and host autophagy in cancer metabolism. Genes Dev. 33, 610-619 (2019)

29. Karanasios, E., Stapleton, E., Manifava, M., Kaizuka, T., Mizushima, N., Walker, S.A., et al.: Dynamic association of the ULK1 complex with omegasomes during autophagy induction. J. Cell Sci. 126, 5224-5238 (2013)
30. Koyama-Honda, I., Itakura, E., Fujiwara, T.K., Mizushima, N.: Temporal analysis of recruitment of mammalian ATG proteins to the autophagosome formation site. Autophagy. 9, 1491-1499 (2013)

31. Ktistakis, N.T., Karanasios, E., Manifava, M.: Dynamics of autophagosome formation: a pulse and a sequence of waves. Biochem. Soc. Trans. 42, 1389-1395 (2014)

32. Condon, K.J., Sabatini, D.M.: Nutrient regulation of mTORC1 at a glance. J. Cell Sci. 132, jes222570 (2019)

33. Axe, E.L., Walker, S.A., Manifava, M., Chandra, P., Roderick, H.L., Habermann, A., et al.: Autophagosome formation from membrane compartments enriched in phosphatidylinositol 3 -phosphate and dynamically connected to the endoplasmic reticulum. J. Cell Biol. 182, 685-701 (2008)

34. Dooley, H.C., Razi, M., Polson, H.E., Girardin, S.E., Wilson, M.I., Tooze, S.A.: WIPI2 links LC3 conjugation with PI3P, autophagosome formation, and pathogen clearance by recruiting Atg12-5-16L1. Mol. Cell. (2014)

35. Reuter, G., Gabius, H.J.: Eukaryotic glycosylation: whim of nature or multipurpose tool? Cell Mol. Life Sci. 55, 368-422 (1999)

36. Schengrund, C.L.: Gangliosides: glycosphingolipids essential for normal neural development and function. Trends Biochem. Sci. 40, 397-406 (2015)

37. Kopitz, J.: Lipid glycosylation: a primer for histochemists and cell biologists. Histochem. Cell Biol. 147, 175-198 (2017)

38. Sharon, N.: Complex Carbohydrates. Their chemistry, biosynthesis, and functions. Reading, MA, USA: Addison-Wesley Publ. Co. (1975)

39. Roseman, S.: Reflections on glycobiology. J. Biol. Chem. 276, 41527-41542 (2001)

40. Gabius, H.J.: editor. The Sugar Code. Fundamentals of glycosciences. Weinheim, Germany: Wiley-VCH (2009)

41. Gabius, H.J., Roth, J.: An introduction to the sugar code. Histochem. Cell Biol. 147, 111-117 (2017)

42. Farquhar, M.G., Palade, G.E.: The Golgi apparatus (complex)(1954-1981)-from artifact to center stage. J. Cell Biol. 91, 77s-103s (1981)

43. Kornfeld, R., Kornfeld, S.: Assembly of asparagine-linked oligosaccharides. Annu. Rev. Biochem. 54, 631-664 (1985)

44. Roth, J.: Subcellular organization of glycosylation in mammalian cells. Biochim. Biophys. Acta. 906, 405-436 (1987)

45. Brockhausen, I., Schachter, H.: Glycosyltransferases involved in $\mathrm{N}$ - and $\mathrm{O}$-glycan biosynthesis. In: Gabius, H.-J., Gabius, S. (eds.) Glycosciences: Status and perspectives, pp. 79-113. Chapman \& Hall, London - Weinheim (1997)

46. Pavelka, M.: Topology of glycosylation - a histochemist's view. In: Gabius, H.-J., Gabius, S. (eds.) Glycosciences: Status and perspectives, pp. 115-120. Chapman \& Hall, London - Weinheim (1997)

47. Droscher, A.: 1998: the centenary of the discovery of the Golgi apparatus. Glycoconj. J. 15, 733-736 (1998)

48. Corfield, A.P.: Eukaryotic protein glycosylation: a primer for histochemists and cell biologists. Histochem. Cell Biol. 147, 119-147 (2017)

49. Kaltner, H., Abad-Rodríguez, J., Corfield, A.P., Kopitz, J., Gabius, H.-J.: The sugar code: letters and vocabulary, writers, editors and readers and biosignificance of functional glycanlectin pairing. Biochem. J. 476, 2623-2655 (2019)

50. Boyd, W.C., Shapleigh, E.: Specific precipitating activity of plant agglutinins (lectins). Science. 119, 419 (1954)

51. Manning, J.C., Romero, A., Habermann, F.A., García Caballero, G., Kaltner, H., Gabius, H.J.: Lectins: a primer for histochemists and cell biologists. Histochem. Cell Biol. 147, 199-222 (2017) 
52. Kaltner, H., García Caballero, G., Ludwig, A.-K., Manning, J.C., Gabius, H.-J.: From glycophenotyping by (plant) lectin histochemistry to defining functionality of glycans by pairing with endogenous lectins. Histochem. Cell Biol. 149, 547-568 (2018)

53. Solis, D., Bovin, N.V., Davis, A.P., Jimenez-Barbero, J., Romero, A., Roy, R., et al.: A guide into glycosciences: How chemistry, biochemistry and biology cooperate to crack the sugar code. Biochim. Biophys. Acta. 1850, 186-235 (2015)

54. Gabius, H.J., Manning, J.C., Kopitz, J., Andre, S., Kaltner, H.: Sweet complementarity: the functional pairing of glycans with lectins. Cell Mol. Life Sci. 73, 1989-2016 (2016)

55. Breitling J, Aebi M. N-linked protein glycosylation in the endoplasmic reticulum. Cold Spring Harb. Perspect. Biol. 5, a013359 (2013)

56. Joshi, H.J., Narimatsu, Y., Schjoldager, K.T., Tytgat, H.L.P., Aebi, M., Clausen, H., et al.: SnapShot: O-glycosylation pathways across kingdoms. Cell. 172, 632-632.e2 (2018)

57. Ma, J., Wu, C., Hart, G.W.: Analytical and biochemical perspectives of protein O-GlcNAcylation. Chem. Rev. 121, 1513-1581 (2021)

58. Konrad, R.J., Kudlow, J.E.: The role of O-linked protein glycosylation in beta-cell dysfunction. Int. J. Mol. Med. 10, 535-539 (2002)

59. Luther, K.B., Haltiwanger, R.S.: Role of unusual O-glycans in intercellular signaling. Int. J. Biochem. Cell Biol. 41, 1011-1024 (2009)

60. Holdener, B.C., Haltiwanger, R.S.: Protein O-fucosylation: structure and function. Curr. Opin. Struct. Biol. 56, 78-86 (2019)

61. Stechly, L., Morelle, W., Dessein, A.F., Andre, S., Grard, G., Trinel, D., et al.: Galectin-4-regulated delivery of glycoproteins to the brush border membrane of enterocyte-like cells. Traffic. 10, 438-450 (2009)

62. Velasco, S., Diez-Revuelta, N., Hernandez-Iglesias, T., Kaltner, H., Andre, S., Gabius, H.J., et al.: Neuronal Galectin-4 is required for axon growth and for the organization of axonal membrane L1 delivery and clustering. J. Neurochem. 125, 49-62 (2013)

63. Murphy. P.V., Romero, A., Xiao, Q., Ludwig, A.K., Jogula, S., Shilova, N.V, et al.: Probing sulfatide-tissue lectin recognition with functionalized glycodendrimersomes. iScience. 24, 101919 (2021)

64. Lahiri, S., Futerman, A.H.: The metabolism and function of sphingolipids and glycosphingolipids. Cell Mol. Life Sci. 64, 2270-2284 (2007)

65. Liu, Y.S., Fujita, M.: Mammalian GPI-anchor modifications and the enzymes involved. Biochem. Soc. Trans. 48, 1129-1138 (2020)

66. Shams-Eldin, H., Debierre-Grockiego, F., Schwarz, R.T.: Glycosylphosphatidylinositol anchors: structure, biosynthesis and functions. In: Gabius, H.-J. (ed.) The Sugar Code Fundamentals of glycosciences, pp. 155-173. Wiley-VCH, Weinhaim, Germany (2009)

67. Schulze, H., Kolter, T., Sandhoff, K.: Principles of lysosomal membrane degradation: Cellular topology and biochemistry of lysosomal lipid degradation. Biochim. Biophys. Acta. 1793, 674-683 (2009)

68. Schwake, M., Schroder, B., Saftig, P.: Lysosomal membrane proteins and their central role in physiology. Traffic. 14, 739-748 (2013)

69. Xiong, J., Zhu, M.X.: Regulation of lysosomal ion homeostasis by channels and transporters. Sci. China Life Sci. 59, 777-791 (2016)

70. Gabius, H.J., Kaltner, H., Kopitz, J., Andre, S.: The glycobiology of the CD system: a dictionary for translating marker designations into glycan/lectin structure and function. Trends Biochem. Sci. 40, 360-376 (2015)

71. Maemura, K., Fukuda, M.: Sialyl Lex structures in O-glycans attached to lysosomal membrane glycoproteins, lamp-1 and lamp-2. Comparison to those in N-glycans. Tetrahedron: Asymmetry. 5, 2093-108 (1994)

72. Mego, J.L.: The ATP-dependent proton pump in lysosome membranes: still a valid hypothesis. FEBS Lett. 107, 113-116 (1979)

73. Saftig, P., Klumperman, J.: Lysosome biogenesis and lysosomal membrane proteins: trafficking meets function. Nat. Rev. Mol. Cell Biol. 10, 623-635 (2009)

74. Sardiello, M., Palmieri, M., di Ronza, A., Medina, D.L., Valenza, M., Gennarino, V.A., et al.: A gene network regulating lysosomal biogenesis and function. Science. 325, 473-477 (2009)

75. Hemesath, T.J., Steingrimsson, E., McGill, G., Hansen, M.J., Vaught, J., Hodgkinson, C.A., et al.: Microphthalmia, a critical factor in melanocyte development, defines a discrete transcription factor family. Genes Dev. 8, 2770-2780 (1994)

76. Kuiper, R.P., Schepens, M., Thijssen, J., Schoenmakers, E.F., van Kessel, A.G.: Regulation of the MiTF/TFE bHLH-LZ transcription factors through restricted spatial expression and alternative splicing of functional domains. Nucleic Acids Res. 32, 2315-2322 (2004)

77. Roczniak-Ferguson, A., Petit, C.S., Froehlich, F., Qian, S., Ky, J., Angarola, B, et al.: The transcription factor TFEB links mTORC1 signaling to transcriptional control of lysosome homeostasis. Sci. Signal. 5, ra42 (2021)

78. Martina, J.A., Chen, Y., Gucek, M., Puertollano, R.: MTORC1 functions as a transcriptional regulator of autophagy by preventing nuclear transport of TFEB. Autophagy. 8, 903-914 (2012)

79. Settembre, C., Di Malta, C., Polito, V.A., Garcia Arencibia, M., Vetrini, F., Erdin, S., et al.: TFEB links autophagy to lysosomal biogenesis. Science. 332, 1429-1433 (2011)

80. Powis, K., De Virgilio, C.: Conserved regulators of Rag GTPases orchestrate amino acid-dependent TORC1 signaling. Cell Discov. 2, 15049 (2016)

81. Medina, D.L., Di Paola, S., Peluso, I., Armani, A., De Stefani, D., Venditti, R., et al.: Lysosomal calcium signalling regulates autophagy through calcineurin and TFEB. Nat. Cell Biol. 17, 288-299 (2015)

82. Braulke, T., Bonifacino, J.S.: Sorting of lysosomal proteins. Biochim. Biophys. Acta. 1793, 605-614 (2009)

83. Ghosh, P., Dahms, N.M., Kornfeld, S.: Mannose 6-phosphate receptors: new twists in the tale. Nat. Rev. Mol. Cell Biol. 4, 202-212 (2003)

84. Reczek, D., Schwake, M., Schroder, J., Hughes, H., Blanz, J., Jin, X., et al.: LIMP-2 is a receptor for lysosomal mannose6-phosphate-independent targeting of beta-glucocerebrosidase. Cell. 131, 770-783 (2007)

85. Rohrer, J., Schweizer, A., Russell, D., Kornfeld, S.: The targeting of Lamp1 to lysosomes is dependent on the spacing of its cytoplasmic tail tyrosine sorting motif relative to the membrane. J. Cell Biol. 132, 565-576 (1996)

86. Geisler, C., Dietrich, J., Nielsen, B.L., Kastrup, J., Lauritsen, J.P., Odum, N., et al.: Leucine-based receptor sorting motifs are dependent on the spacing relative to the plasma membrane. J. Biol. Chem. 273, 21316-21323 (1998)

87. Perera, R.M., Zoncu, R.: The lysosome as a regulatory hub. Annu. Rev. Cell Dev. Biol. 32, 223-253 (2016)

88. Reddy, A., Caler, E.V., Andrews, N.W.: Plasma membrane repair is mediated by $\mathrm{Ca}(2+)$-regulated exocytosis of lysosomes. Cell. 106, 157-169 (2001)

89. Michelet, X., Tuli, A., Gan, H., Geadas, C., Sharma, M., Remold, H.G., et al.: Lysosome-mediated plasma membrane repair Is dependent on the small GTPase Arl8b and determines cell death type in Mycobacterium tuberculosis infection. J. Immunol. 200, 3160-3169 (2018)

90. Rao, S.K., Huynh, C., Proux-Gillardeaux, V., Galli, T., Andrews, N.W.: Identification of SNAREs involved in synaptotagmin VII-regulated lysosomal exocytosis. J. Biol. Chem. 279, 20471-20479 (2004) 
91. Aureli, M., Loberto, N., Chigorno, V., Prinetti, A., Sonnino, S.: Remodeling of sphingolipids by plasma membrane associated enzymes. Neurochem. Res. 36, 1636-1644 (2011)

92. Appelqvist, H., Waster, P., Kagedal, K., Ollinger, K.: The lysosome: from waste bag to potential therapeutic target. J. Mol. Cell Biol. 5, 214-226 (2013)

93. Goldstein, J.L., Dana, S.E., Faust, J.R., Beaudet, A.L., Brown. M.S.: Role of lysosomal acid lipase in the metabolism of plasma low density lipoprotein. Observations in cultured fibroblasts from a patient with cholesteryl ester storage disease. J. Biol. Chem. 250, 8487-95 (1975)

94. Subramanian, K., Balch, W.E.: NPC1/NPC2 function as a tag team duo to mobilize cholesterol. Proc. Natl. Acad. Sci. USA. 105, 15223-15224 (2008)

95. Boya, P., Kroemer, G.: Lysosomal membrane permeabilization in cell death. Oncogene. 27, 6434-6451 (2008)

96. De Duve, C.: The lysosome concept. In: Cameron AVSdRaMP, editor. Ciba Foundation Symposium - Anterior pituitary secretion (Book I of Colloquia on Endocrinology) 1-35 (1963)

97. Swanson, J.A.: Shaping cups into phagosomes and macropinosomes. Nat. Rev. Mol. Cell Biol. 9, 639-649 (2008)

98. Groves, E., Dart, A.E., Covarelli, V., Caron, E.: Molecular mechanisms of phagocytic uptake in mammalian cells. Cell Mol. Life Sci. 65, 1957-1976 (2008)

99. Kerr, M.C., Teasdale, R.D.: Defining macropinocytosis. Traffic. 10, 364-371 (2009)

100. Thottacherry, J.J., Sathe, M., Prabhakara, C., Mayor, S.: Spoiled for choice: diverse endocytic pathways function at the cell surface. Ann. Rev. Cell Dev. Biol. 35, 55-84 (2019)

101. Kaksonen, M., Roux, A.: Mechanisms of clathrin-mediated endocytosis. Nat. Rev. Mol. Cell Biol. 19, 313-326 (2018)

102. McMahon, H.T., Boucrot, E.: Molecular mechanism and physiological functions of clathrin-mediated endocytosis. Nat. Rev. Mol. Cell Biol. 12, 517-533 (2011)

103. Mettlen, M., Chen, P.H., Srinivasan, S., Danuser, G., Schmid, S.L.: Regulation of clathrin-mediated endocytosis. Ann. Rev. Biochem. 87, 871-896 (2018)

104. Shafaq-Zadah, M., Dransart, E., Johannes, L.: Clathrin-independent endocytosis, retrograde trafficking, and cell polarity. Curr. Op. Cell Biol. 65, 112-121 (2020)

105. Hemalatha, A., Mayor, S.: Recent advances in clathrin-independent endocytosis. F1000Res. 8, F1000 Faculty Rev-138 (2019)

106. Mayor, S., Parton, R.G., Donaldson. J.G.: Clathrin-independent pathways of endocytosis. Cold Spring Harb. Perspec. Biol. 6, a016758 (2014)

107. Doherty, G.J., McMahon, H.T.: Mechanisms of endocytosis. Ann. Rev. Biochem. 78, 857-902 (2009)

108. Haglund, K., Dikic, I.: The role of ubiquitylation in receptor endocytosis and endosomal sorting. J. Cell Sci. 125, 265-275 (2012)

109. Sorkin, A., von Zastrow, M.: Endocytosis and signalling: intertwining molecular networks. Nat. Rev. Mol. Cell Biol. 10, 609$622(2009)$

110. Ashwell, G., Morell, A.G.: The role of surface carbohydrates in the hepatic recognition and transport of circulating glycoproteins. Adv. Enzymol. Relat. Areas Mol. Biol. 41, 99-128 (1974)

111. Ashwell, G., Harford, J.: Carbohydrate-specific receptors of the liver. Annu. Rev. Biochem. 51, 531-554 (1982)

112. Gabius, H.J.: Detection and functions of mammalian lectins-with emphasis on membrane lectins. Biochim. Biophys. Acta. 1071, 1-18 (1991)

113. Kohno, T., Wada, A., Igarashi, Y.: N-glycans of sphingosine 1-phosphate receptor Edg-1 regulate ligand-induced receptor internalization. FASEB J. 16, 983-992 (2002)

114. Min, C., Zheng, M., Zhang, X., Guo, S., Kwon, K.J., Shin, C.Y., et al.: N-linked Glycosylation on the N-terminus of the dopamine D2 and D3 receptors determines receptor association with specific microdomains in the plasma membrane. Biochim. Biophys. Acta. 1853, 41-51 (2015)

115. Altschuler, Y., Kinlough, C.L., Poland, P.A., Bruns, J.B., Apodaca, G., Weisz, O.A., et al.: Clathrin-mediated endocytosis of MUC1 is modulated by its glycosylation state. Mol. Biol. Cell. 11, 819-831 (2000)

116. Partridge, E.A., Le Roy, C., Di Guglielmo, G.M., Pawling, J., Cheung, P., Granovsky, M., et al.: Regulation of cytokine receptors by Golgi N-glycan processing and endocytosis. Science. 306, 120-124 (2004)

117. Rosen, S.D.: Ligands for L-selectin: homing, inflammation, and beyond. Annu. Rev. Immunol. 22, 129-156 (2004)

118. van Kooyk, Y., Rabinovich, G.A.: Protein-glycan interactions in the control of innate and adaptive immune responses. Nat. Immunol. 9, 593-601 (2008)

119. Van Breedam, W., Pohlmann, S., Favoreel, H.W., de Groot, R.J., Nauwynck, H.J.: Bitter-sweet symphony: glycan-lectin interactions in virus biology. FEMS Microbiol. Rev. 38, 598-632 (2014)

120. Aigal, S., Claudinon, J., Römer, W.: Plasma membrane reorganization: A glycolipid gateway for microbes. Biochim. Biophys. Acta. 1853, 858-871 (2015)

121. Sych, T., Mely, Y., Römer, W.: Lipid self-assembly and lectininduced reorganization of the plasma membrane. Philos. Trans. R. Soc. Lon. B: Biol. Sci. 373, 20170117 (2018)

122. Schubert, T., Römer, W.: How synthetic membrane systems contribute to the understanding of lipid-driven endocytosis. Biochim. Biophys. Acta. 1853, 2992-3005 (2015)

123. Omidvar, R., Römer, W.: Glycan-decorated protocells: novel features for rebuilding cellular processes. Interface Focus. 9, 20180084 (2019)

124. Kociurzynski, R., Beck, S.D., Bouhon, J.B., Römer, W., Knecht, V.: Binding of SV40's viral capsid protein VP1 to its glycosphingolipid receptor GM1 induces negative membrane curvature: A molecular dynamics study. Langmuir. 35, 3534-3544 (2019)

125. Simons, K., Ikonen, E.: Functional rafts in cell membranes. Nature. 387, 569-572 (1997)

126. Fra, A.M., Williamson, E., Simons, K., Parton, R.G.: Detergentinsoluble glycolipid microdomains in lymphocytes in the absence of caveolae. J. Biol. Chem. 269, 30745-30748 (1994)

127. Schütte, O.M., Ries, A., Orth, A., Patalag, L.J., Römer, W., Steinem, C., et al.: Influence of Gb3 glycosphingolipids differing in their fatty acid chain on the phase behaviour of solid supported membranes: chemical syntheses and impact of Shiga toxin binding. Chem. Sci. 5, 3104-3114 (2014)

128. Mahfoud, R., Manis, A., Lingwood, C.A.: Fatty acid-dependent globotriaosyl ceramide receptor function in detergent resistant model membranes. J. Lipid Res. 50, 1744-1755 (2009)

129. Schubert, T., Sych, T., Madl, J., Xu, M., Omidvar, R., Patalag, L.J., et al.: Differential recognition of lipid domains by two Gb3-binding lectins. Sci. Rep. 10, 9752 (2020)

130. Thuenauer, R., Landi, A., Trefzer, A., Altmann, S., Wehrum, S., Eierhoff, T, et al.: The Pseudomonas aeruginosa lectin LecB causes integrin internalization and inhibits epithelial wound healing. mBio. 1, 11:e03260-19 (2021)

131. Darkow, E., Rog-Zielinska, E.A., Madl, J., Brandel, A., Siukstaite, L., Omidvar, R., et al.: The lectin LecA sensitizes the human stretch-activated channel TREK-1 but not Piezo1 and binds selectively to cardiac non-myocytes. Front. Physiol. 11, 457 (2020)

132. Arnaud, J., Claudinon, J., Trondle, K., Trovaslet, M., Larson, G., Thomas, A., et al.: Reduction of lectin valency drastically changes glycolipid dynamics in membranes but not surface avidity. ACS Chem. Biol. 8, 1918-1924 (2013)

133. Römer, W., Berland, L., Chambon, V., Gaus, K., Windschiegl, B., Tenza, D., et al.: Shiga toxin induces tubular membrane invaginations for its uptake into cells. Nature. 450, 670-675 (2007) 
134. Windschiegl, B., Orth, A., Römer, W., Berland, L., Stechmann, B., Bassereau, P, et al.: Lipid reorganization induced by Shiga toxin clustering on planar membranes. PLoS One. 4, e6238 (2009)

135. Kabbani, A.M., Raghunathan, K., Lencer, W.I., Kenworthy, A.K., Kelly, C.V.: Structured clustering of the glycosphingolipid GM1 is required for membrane curvature induced by cholera toxin. Proc. Natl. Acad. Sci. USA. 117, 14978-14986 (2020)

136. Johannes, L., Römer, W.: Shiga toxins-from cell biology to biomedical applications. Nat. Rev. Microbiol. 8, 105-116 (2010)

137. Pezeshkian, W., Hansen, A.G., Johannes, L., Khandelia, H., Shillcock, J.C., Kumar, P.B., et al.: Membrane invagination induced by Shiga toxin B-subunit: from molecular structure to tube formation. Soft Matter. 12, 5164-5171 (2016)

138. Kociurzynski, R., Makshakova, O.N., Knecht, V., Römer, W. Multiscale molecular dynamics studies reveal different modes of receptor clustering by Gb3-binding lectins. J. Chem. Theory Comput. 17, 2488-2501 (2021)

139. Arnaud, J., Trondle, K., Claudinon, J., Audfray, A., Varrot, A., Römer, W., et al.: Membrane deformation by neolectins with engineered glycolipid binding sites. Angew. Chem. Int. Ed. Engl. 53, 9267-9270 (2014)

140. Ewers, H., Römer, W., Smith, A.E., Bacia, K., Dmitrieff, S., Chai, W., et al.: GM1 structure determines SV40-induced membrane invagination and infection. Nat. Cell Biol. 12, 11-18 (2010)

141. Rydell, G.E., Svensson, L., Larson, G., Johannes, L., Römer, W.: Human GII.4 norovirus VLP induces membrane invaginations on giant unilamellar vesicles containing secretor gene dependent alpha1,2-fucosylated glycosphingolipids. Biochim. Biophys. Acta. 1828, 1840-1845 (2013)

142. Eierhoff, T., Bastian, B., Thuenauer, R., Madl, J., Audfray, A., Aigal, S., et al.: A lipid zipper triggers bacterial invasion. Proc. Natl. Acad. Sci. USA. 111, 12895-12900 (2014)

143. Omidvar, R., Ayala, Y.A., Brandel, A., Hasenclever, L., Helmstadter, M., Rohrbach, A., et al.: Quantification of nanoscale forces in lectin-mediated bacterial attachment and uptake into giant liposomes. Nanoscale. 13, 4016-4028 (2021)

144. Zheng, S., Eierhoff, T., Aigal, S., Brandel, A., Thuenauer, R., de Bentzmann, S., et al.: The Pseudomonas aeruginosa lectin LecA triggers host cell signalling by glycosphingolipid-dependent phosphorylation of the adaptor protein CrkII. Biochim. Biophys. Acta Mol. Cell Res. 1864, 1236-1245 (2017)

145. Johannes, L., Jacob, R., Leffler, H.: Galectins at a glance. J. Cell Sci. 131, jcs208884 (2018)

146. Hirabayashi J. (ed): Recent topics on galectins. Trends Glycosci Glycotechnol. 45, 1-180 (1997)

147. Hirabayashi J. (ed): Special issue on galectins. Trends Glycosci Glycotechnol. 30, SE1-SE223 (2018)

148. Lakshminarayan, R., Wunder, C., Becken, U., Howes, M.T., Benzing, C., Arumugam, S., et al.: Galectin-3 drives glycosphingolipid-dependent biogenesis of clathrin-independent carriers. Nat. Cell Biol. 16, 595-606 (2014)

149. Nabi, I.R., Shankar, J., Dennis, J.W.: The galectin lattice at a glance. J. Cell Sci. 128, 2213-2219 (2015)

150. Mathew, M.P., Donaldson, J.G.: Distinct cargo-specific response landscapes underpin the complex and nuanced role of galectinglycan interactions in clathrin-independent endocytosis. J. Biol. Chem. 293, 7222-7237 (2018)

151. Mathew, M.P., Tan, E., Saeui, C.T., Bovonratwet, P., Sklar, S., Bhattacharya, R., et al.: Metabolic flux-driven sialylation alters internalization, recycling, and drug sensitivity of the epidermal growth factor receptor (EGFR) in SW1990 pancreatic cancer cells. Oncotarget. 7, 66491-66511 (2016)

152. Marrack, J.R.: The chemistry of antigens and antibodies, p. 197. H.M. Stationery Office, London (1934)
153. Schedlbauer, A., Gilles, U., Ludwig, A.-K., Adler, A., Kaltner, H., Lindner, I., et al.: Characterizing ligand-induced conformational changes in clinically relevant galectin- 1 by $\mathrm{H}(\mathrm{N}) / \mathrm{H} 2 \mathrm{O}$ (D2O) exchange. Biochimie. 187, 48-56 (2021)

154. Demetriou, M., Nabi, I.R., Dennis, J.W.: Galectins as adaptors: linking glycosylation and metabolism with extracellular cues. Trends Glycosci Glycotechnol. 30, SE167-SE77 (2018)

155. Sharon, N.: When lectin meets oligosaccharide. Nat. Struct. Biol. 1, 843-845 (1994)

156. Chiu, Y.P., Sun, Y.C., Qiu, D.C., Lin, Y.H., Chen, Y.Q., Kuo, J.C., et al.: Liquid-liquid phase separation and extracellular multivalent interactions in the tale of galectin-3. Nat. Commun. 11, 1229 (2020)

157. Farhadi, S.A., Liu, R., Becker, M.W., Phelps, E.A., Hudalla, G.A.: Physical tuning of galectin-3 signaling. Proc. Natl. Acad. Sci. USA. 118, e2024117118 (2021)

158. Ludwig, A.K., Michalak, M., Xiao, Q., Gilles, U., Medrano, F.J., Ma, H., et al.: Design-functionality relationships for adhesion/ growth-regulatory galectins. Proc. Natl. Acad. Sci. USA. 116, 2837-2842 (2019)

159. Garcia Caballero, G., Beckwith, D., Shilova, N.V., Gabba, A., Kutzner, T.J., Ludwig, A.K., et al.: Influence of protein (human galectin-3) design on aspects of lectin activity. Histochem. Cell Biol. 154, 135-153 (2020)

160. Young, A.R., Chan, E.Y., Hu, X.W., Kochl, R., Crawshaw, S.G., High, S., et al.: Starvation and ULK1-dependent cycling of mammalian Atg9 between the TGN and endosomes. J. Cell Sci. 119, 3888-3900 (2006)

161. Guardia, C.M., Tan, X.F., Lian, T., Rana, M.S., Zhou, W., Christenson, E.T, et al.: Structure of human ATG9A, the only transmembrane protein of the core autophagy machinery. Cell Rep. 31, 31107837 (2020)

162. Matoba, K., Kotani, T., Tsutsumi, A., Tsuji, T., Mori, T., Noshiro, D., et al.: Atg9 is a lipid scramblase that mediates autophagosomal membrane expansion. Nat. Struct. Mol. Biol. 27, 1185-1193 (2020)

163. Maeda, S., Yamamoto, H., Kinch, L.N., Garza, C.M., Takahashi, S., Otomo, C., et al.: Structure, lipid scrambling activity and role in autophagosome formation of ATG9A. Nat. Struct. Mol. Biol. 27, 1194-1201 (2020)

164. Kishi-Itakura, C., Koyama-Honda, I., Itakura, E., Mizushima, N.: Ultrastructural analysis of autophagosome organization using mammalian autophagy-deficient cells. J. Cell Sci. 127, 4089$4102(2014)$

165. Popovic, D., Dikic, I.: TBC1D5 and the AP2 complex regulate ATG9 trafficking and initiation of autophagy. EMBO Rep. 15, 392-401 (2014)

166. Puri, C., Renna, M., Bento, C.F., Moreau, K., Rubinsztein, D.C.: Diverse autophagosome membrane sources coalesce in recycling endosomes. Cell. 154, 1285-1299 (2013)

167. Takahashi, Y., Meyerkord, C.L., Hori, T., Runkle, K., Fox, T.E., Kester, M., et al.: Bif-1 regulates Atg9 trafficking by mediating the fission of Golgi membranes during autophagy. Autophagy. 7, 61-73 (2011)

168. He, S., Ni, D., Ma, B., Lee, J.H., Zhang, T., Ghozalli, I., et al.: PtdIns(3)P-bound UVRAG coordinates Golgi-ER retrograde and Atg9 transport by differential interactions with the ER tether and the beclin 1 complex. Nat. Cell Biol. 15, 1206-1219 (2013)

169. Sawa-Makarska, J., Baumann, V., Coudevylle, N., von Bulow, S., Nogellova, V., Abert, C., et al.: Reconstitution of autophagosome nucleation defines Atg9 vesicles as seeds for membrane formation. Science. 369, eaaz7714 (2020)

170. Tang, Z., Takahashi, Y., He, H., Hattori, T., Chen, C., Liang, X., et al.: TOM40 Targets Atg2 to Mitochondria-Associated ER Membranes for Phagophore Expansion. Cell Rep. 28, 1744-1757 (2019) 
171. Maeda, S., Otomo, C., Otomo, T.: The autophagic membrane tether ATG2A transfers lipids between membranes. eLife. 8, e45777 (2019)

172. Osawa, T., Ishii, Y., Noda, N.N.: Human ATG2B possesses a lipid transfer activity which is accelerated by negatively charged lipids and WIPI4. Genes Cells. 25, 65-70 (2020)

173. Valverde, D.P., Yu, S., Boggavarapu, V., Kumar, N., Lees, J.A., Walz, T., et al.: ATG2 transports lipids to promote autophagosome biogenesis. J. Cell Biol. 218, 1787-1798 (2019)

174. Osawa, T., Kotani, T., Kawaoka, T., Hirata, E., Suzuki, K., Nakatogawa, H., et al.: Atg2 mediates direct lipid transfer between membranes for autophagosome formation. Nat. Struct. Mol. Biol. 26, 281-288 (2019)

175. Matoba, K., Noda, N.N.: Secret of Atg9: lipid scramblase activity drives de novo autophagosome biogenesis. Cell Death Differ. 27, 3386-3388 (2020)

176. Kotani, T., Kirisako, H., Koizumi, M., Ohsumi, Y., Nakatogawa, H.: The Atg2-Atg18 complex tethers pre-autophagosomal membranes to the endoplasmic reticulum for autophagosome formation. Proc. Natl. Acad. Sci. USA. 115, 10363-10368 (2018)

177. Staudt, C., Gilis, F., Boonen, M., Jadot, M.: Molecular determinants that mediate the sorting of human ATG9A from the endoplasmic reticulum. Biochim. Biophys. Acta. 1863, 2299-2310 (2016)

178. Yamamoto, A., Masaki, R., Tashiro, Y.: Characterization of the isolation membranes and the limiting membranes of autophagosomes in rat hepatocytes by lectin cytochemistry. J. Histochem. Cytochem. 38, 573-580 (1990)

179. Matarrese, P., Garofalo, T., Manganelli, V., Gambardella, L., Marconi, M., Grasso, M., et al.: Evidence for the involvement of GD3 ganglioside in autophagosome formation and maturation. Autophagy. 10, 750-765 (2014)

180. Liu, Y., Yao, R.Z., Lian, S., Liu, P., Hu, Y.J., Shi, H.Z., et al.: O-GlcNAcylation: the "stress and nutrition receptor" in cell stress response. Cell Stress Chaperones in press (2021)

181. Pyo, K.E., Kim, C.R., Lee, M., Kim, J.S., Kim, K.I., Baek, S.H.: ULK1 O-GlcNAcylation is crucial for activating VPS34 via ATG14L during autophagy initiation. Cell Rep. 25, 28782890 (2018)

182. Marsh, S.A., Powell, P.C., Dell'italia, L.J., Chatham, J.C.: Cardiac O-GlcNAcylation blunts autophagic signaling in the diabetic heart. Life Sci. 92, 648-656 (2013)

183. Guo, B., Liang, Q., Li, L., Hu, Z., Wu, F., Zhang, P., et al.: O-GlcNAc-modification of SNAP-29 regulates autophagosome maturation. Nat. Cell Biol. 16, 1215-1226 (2014)

184. Buraschi, S., Neill, T., Goyal, A., Poluzzi, C., Smythies, J., Owens, R.T., et al.: Decorin causes autophagy in endothelial cells via Peg3. Proc. Natl. Acad. Sci. USA. 110, E2582-E2591 (2013)

185. Kalas, W., Swiderek, E., Switalska, M., Wietrzyk, J., Rak, J., Strzadala, L.: Thrombospondin-1 receptor mediates autophagy of RAS-expressing cancer cells and triggers tumour growth inhibition. Anticancer Res. 33, 1429-1438 (2013)

186. Neill, T., Kapoor, A., Xie, C., Buraschi, S., Iozzo, R.V.: A functional outside-in signaling network of proteoglycans and matrix molecules regulating autophagy. Matrix Biol. in press (2021)

187. Avivar-Valderas, A., Salas, E., Bobrovnikova-Marjon, E., Diehl, J.A., Nagi, C., Debnath, J., et al.: PERK integrates autophagy and oxidative stress responses to promote survival during extracellular matrix detachment. Mol. Cell Biol. 31, 3616-3629 (2011)

188. Fung, C., Lock, R., Gao, S., Salas, E., Debnath, J.: Induction of autophagy during extracellular matrix detachment promotes cell survival. Mol. Biol. Cell. 19, 797-806 (2008)

189. Roy, B., Pattanaik, A.K., Das, J., Bhutia, S.K., Behera, B., Singh, P., et al.: Role of PI3K/Akt/mTOR and MEK/ERK pathway in Concanavalin A induced autophagy in HeLa cells. Chem. Biol. Interact. 210, 96-102 (2014)
190. Pratt, J., Annabi, B.: Induction of autophagy biomarker BNIP3 requires a JAK2/STAT3 and MT1-MMP signaling interplay in Concanavalin-A-activated U87 glioblastoma cells. Cell Signal. 26, 917-924 (2014)

191. Fahie, K., Zachara, N.E.: Molecular functions of glycoconjugates in autophagy. J. Mol. Biol. 428, 3305-3324 (2016)

192. Ninagawa, S., George, G., Mori, K.: Mechanisms of productive folding and endoplasmic reticulum-associated degradation of glycoproteins and non-glycoproteins. Biochim. Biophys. Acta. 1865, 129812 (2021)

193. Helenius, A., Aebi, M.: Roles of N-linked glycans in the endoplasmic reticulum. Annu. Rev. Biochem. 73, 1019-1049 (2004)

194. Appenzeller-Herzog, C., Hauri, H.P.: The ER-Golgi intermediate compartment (ERGIC): in search of its identity and function. J. Cell Sci. 119, 2173-2183 (2006)

195. Caramelo, J.J., Parodi, A.J.: A sweet code for glycoprotein folding. FEBS Lett. 589, 3379-3387 (2015)

196. McCaffrey, K., Braakman, I.: Protein quality control at the endoplasmic reticulum. Essays Biochem. 60, 227-235 (2016)

197. Roth, J., Zuber, C.: Quality control of glycoprotein folding and ERAD: the role of N-glycan handling, EDEM1 and OS-9. Histochem. Cell Biol. 147, 269-284 (2017)

198. Yoshida, Y., Tanaka, K.: Cytosolic N-Glycans: triggers for ubiquitination directing proteasomal and autophagic degradation: molecular systems for monitoring cytosolic n-glycans as signals for unwanted proteins and organelles. BioEssays. 40, 1700215 (2018)

199. Schrag, J.D., Procopio, D.O., Cygler, M., Thomas, D.Y., Bergeron, J.J.: Lectin control of protein folding and sorting in the secretory pathway. Trends Biochem. Sci. 28, 49-57 (2003)

200. Gesner, B.M., Ginsburg, V.: Effect of glycosidases on the fate of transfused lymphocytes. Proc. Natl. Acad. Sci. USA. 52, 750-755 (1964)

201. Lam, S.T.T., Lim, C.J.: Cancer biology of the endoplasmic reticulum lectin chaperones calreticulin, calnexin and PDIA3/ ERp57. Prog. Mol. Subcell Biol. 59, 181-196 (2021)

202. Lamriben, L., Graham, J.B., Adams, B.M., Hebert, D.N.: N-Glycanbased ER molecular chaperone and protein quality control system: the calnexin binding cycle. Traffic. 17, 308-326 (2016)

203. Nishio, M., Kamiya, Y., Mizushima, T., Wakatsuki, S., Sasakawa, H., Yamamoto, K., et al.: Structural basis for the cooperative interplay between the two causative gene products of combined factor V and factor VIII deficiency. Proc. Natl. Acad. Sci. USA. 107, 4034-4039 (2010)

204. Satoh, T., Nishio, M., Suzuki, K., Yagi-Utsumi, M., Kamiya, Y., Mizushima, T., et al.: Crystallographic snapshots of the EFhand protein MCFD2 complexed with the intracellular lectin ERGIC-53 involved in glycoprotein transport. Acta Crystallogr. 76, F216-F221 (2020)

205. Yoshida, Y., Tanaka, K.: Lectin-like ERAD players in ER and cytosol. Biochim. Biophys. Acta. 1800(172-80), 7 (2010)

206. Benyair, R., Ogen-Shtern, N., Lederkremer, G.Z.: Glycan regulation of ER-associated degradation through compartmentalization. Semin. Cell Dev. Biol. 41, 99-109 (2015)

207. Yoshida, Y., Yasuda, S., Fujita, T., Hamasaki, M., Murakami, A., Kawawaki, J., et al.: Ubiquitination of exposed glycoproteins by $\mathrm{SCF}(\mathrm{FBXO} 27)$ directs damaged lysosomes for autophagy. Proc. Natl. Acad. Sci. USA. 114, 8574-8579 (2017)

208. Eskelinen, E.L., Tanaka, Y., Saftig, P.: At the acidic edge: emerging functions for lysosomal membrane proteins. Trends Cell Biol. 13, 137-145 (2003)

209. Ohannesian, D.W., Lotan, D., Thomas, P., Jessup, J.M., Fukuda, M., Gabius, H.-J., et al.: Carcinoembryonic antigen and other glycoconjugates act as ligands for galectin-3 in human colon carcinoma cells. Cancer Res. 55, 2191-2199 (1995) 
210. Sudhakar, J.N., Lu, H.H., Chiang, H.Y., Suen, C.S., Hwang, M.J., $\mathrm{Wu}, \mathrm{S} . Y$. , et al.: Lumenal Galectin-9-Lamp2 interaction regulates lysosome and autophagy to prevent pathogenesis in the intestine and pancreas. Nat. Commun. 11, 4286 (2020)

211. Schroder, M., Kaufman, R.J.: The mammalian unfolded protein response. Annu. Rev. Biochem. 74, 739-789 (2005)

212. Ron, D., Walter, P.: Signal integration in the endoplasmic reticulum unfolded protein response. Nat. Rev. Mol. Cell Biol. 8, 519-529 (2007)

213. Prasad, V., Greber, U.F.: The endoplasmic reticulum unfolded protein response - homeostasis, cell death and evolution in virus infections. FEMS Microbiol. Rev. in press (2021)

214. Ferro-Novick, S., Reggiori, F., Brodsky, J.L.: ER-phagy, ER homeostasis, and ER quality control: implications for disease. Trends Biochem. Sci. in press (2021)

215. Dewal, M.B., DiChiara, A.S., Antonopoulos, A., Taylor, R.J., Harmon, C.J., Haslam, S.M., et al.: XBP1s links the unfolded protein response to the molecular architecture of mature N-glycans. Chem. Biol. 22, 1301-1312 (2015)

216. Wong, M.Y., Chen, K., Antonopoulos, A., Kasper, B.T., Dewal, M.B., Taylor, R.J., et al.: XBP1s activation can globally remodel $\mathrm{N}$-glycan structure distribution patterns. Proc. Natl. Acad. Sci. USA. 115, E10089-E10098 (2018)

217. Gabius, H.J., Springer, W.R., Barondes, S.H.: Receptor for the cell binding site of discoidin I. Cell. 42, 449-456 (1985)

218. Barondes, S.H.: Bifunctional properties of lectins: lectins redefined. Trends Biochem. Sci. 13, 480-482 (1988)

219. Miller, M.C., Cai, C., Wichapong, K., Bhaduri, S., Pohl, N.L.B., Linhardt, R.J., et al.: Structural insight into the binding of human galectins to corneal keratan sulfate, its desulfated form and related saccharides. Sci. Rep. 10, 15708 (2020)

220. Iwaki, J., Hirabayashi, J.: Carbohydrate-binding specificity of human galectins: an overview by frontal affinity chromatography. Trends Glycosci. Glycotechnol. 30, SE137-SE53 (2018)

221. Sato, S., Nieminen, J.: Seeing strangers or announcing "danger": galectin-3 in two models of innate immunity. Glycoconj. J. 19, 583-591 (2002)

222. Hong, M.H., Weng, I.C., Liu, F.T.: Galectins as intracellular regulators of cellular responses through the detection of damaged endocytic vesicles. Trends Glycosci. Glycotechnol. 30, SE179-SE84 (2018)

223. Sato, S.: Cytosolic galectins and their release and roles as carbohydrate-binding proteins in host-pathogen interaction. Trends Glycosci. Glycotechnol. 30, SE199-SE209 (2018)

224. Teichberg, V.I., Silman, I., Beitsch, D.D., Resheff, G.: A $\beta$-Dgalactoside-binding protein from electric organ tissue of Electrophorus electricus. Proc. Natl. Acad. Sci. USA. 72, 1383-1387 (1975)

225. Barondes, S.H.: Soluble lectins: a new class of extracellular proteins. Science. 223, 1259-1264 (1984)

226. Kasai, K.I., Galectins, H.J.: a family of animal lectins that decipher glycocodes. J. Biochem. 119, 1-8 (1996)

227. Cooper, D.N.W.: Galectinomics: finding themes in complexity. Biochim. Biophys. Acta. 1572, 209-231 (2002)

228. Kaltner, H., Toegel, S., García Caballero, G., Manning, J.C., Ledeen, R.W., Gabius, H.J.: Galectins: their network and roles in immunity/tumor growth control. Histochem. Cell Biol. 147, 239-256 (2017)

229. García Caballero, G., Kaltner, H., Kutzner, T.J., Ludwig, A.-K., Manning, J.C., Schmidt, S., et al.: How galectins have become multifunctional proteins. Histol. Histopathol. 35, 509-539 (2020)

230. Hughes, R.C.: Secretion of the galectin family of mammalian carbohydrate-binding proteins. Biochim. Biophys. Acta. 1473, 172-185 (1999)

231. Kutzner, T.J., Higuero, A.M., Süßmair, M., Kopitz, J., Hingar, M., Díez-Revuelta, N., et al.: How presence of a signal peptide affects human galectins-1 and -4 : clues to explain common absence of a leader sequence among adhesion/growth-regulatory galectins. Biochim. Biophys. Acta. 1864, 129449 (2020)

232. Caberoy, N.B., Alvarado, G., Bigcas, J.-L., Li, W.: Galectin-3 is a new MerTK-specific eat-me signal. J. Cell Physiol. 227, 401-407 (2012)

233. Eckardt, V., Miller, M.C., Blanchet, X., Duan, R., Leberzammer, J., Duchene, J., et al.: Chemokines and galectins form heterodimers to modulate inflammation. EMBO Rep. 21, e47852 (2020)

234. Ford, M.G., Weimar, T., Köhli, T., Woods, R.J.: Molecular dynamics simulations of galectin-1-oligosaccharide complexes reveal the molecular basis for ligand diversity. Proteins. 53, 229-240 (2003)

235. Garin, J., Diez, R., Kieffer, S., Dermine, J.F., Duclos, S., Gagnon, E., et al.: The phagosome proteome: insight into phagosome functions. J. Cell Biol. 152, 165-180 (2001)

236. Dupont, N., Lacas-Gervais, S., Bertout, J., Paz, I., Freche, B., Van Nhieu, G.T., et al.: Shigella phagocytic vacuolar membrane remnants participate in the cellular response to pathogen invasion and are regulated by autophagy. Cell Host Microbe. 6, 137-149 (2009)

237. Beatty, W.L., Rhoades, E.R., Hsu, D.K., Liu, F.-T., Russell, D.G.: Association of a macrophage galactoside-binding protein with Mycobacterium-containing phagosomes. Cell Microbiol. 4, 167-176 (2002)

238. Paz, I., Sachse, M., Dupont, N., Mounier, J., Cederfur, C., Enninga, J., et al.: Galectin-3, a marker for vacuole lysis by invasive pathogens. Cell Microbiol. 12, 530-544 (2010)

239. Feeley, E.M., Pilla-Moffett, D.M., Zwack, E.E., Piro, A.S., Finethy, R., Kolb, J.P., et al.: Galectin-3 directs antimicrobial guanylate binding proteins to vacuoles furnished with bacterial secretion systems. Proc. Natl. Acad. Sci. USA 114, E1698E1706 (2017)

240. Huang, J., Brumell, J.H.: Microbiology: a sweet way of sensing danger. Nature. 482, 316-317 (2012)

241. Thurston, T.L.M., Wandel, M.P., von Muhlinen, N., Foeglein, A., Randow, F.: Galectin 8 targets damaged vesicles for autophagy to defend cells against bacterial invasion. Nature. 482, 414-418 (2012)

242. Kim, B.W., Hong, S.B., Kim, J.H., Kwon, D.H., Song, H.K.: Structural basis for recognition of autophagic receptor NDP52 by the sugar receptor galectin-8. Nat. Commun. 4, 1613 (2013)

243. Li, S., Wandel, M.P., Li, F.D., Liu, Z.H., He, C., Wu, J.H, et al.: Sterical hindrance promotes selectivity of the autophagy cargo receptor NDP52 for the danger receptor galectin-8 in antibacterial autophagy. Sci. Signal. 6, ra9 (2013)

244. Falcon, B., Noad, J., McMahon, H., Randow, F., Goedert, M.: Galectin-8-mediated selective autophagy protects against seeded tau aggregation. J. Biol. Chem. 293, 2438-2451 (2018)

245. Cheng, Y.L.., Wu, Y.W., Kuo, C.F., Lu, S.L., Liu, F.T., Anderson, $\mathrm{R}$, et al.: Galectin-3 inhibits galectin-8/parkin-mediated ubiquitination of group a streptococcus. MBio. e0089917 (2017)

246. Chen, X., Khambu, B., Zhang, H., Gao, W., Li, M., Chen, X., et al.: Autophagy induced by calcium phosphate precipitates targets damaged endosomes. J. Biol. Chem. 289, 11162-11174 (2014)

247. Chauhan, S., Kumar, S., Jain, A., Ponpuak, M., Mudd, M.H., Kimura, T., et al.: TRIMs and galectins globally cooperate and TRIM16 and galectin-3 co-direct autophagy in endomembrane damage homeostasis. Dev. Cell. 39, 13-27 (2016)

248. Hong, M.H., Lin, W.H., Weng, I.C., Hung, H., Chen, H.L., Chen, H.Y., et al.: Intracellular galectins control cellular responses commensurate with cell surface carbohydrate composition. Glycobiology. 30, 36-48 (2020)

249. Fraser, J., Simpson, J., Fontana, R., Kishi-Itakura, C., Ktistakis, N.T., Gammoh, N.: Targeting of early endosomes by autophagy facilitates EGFR recycling and signalling. EMBO Rep. 20, e47734 (2019) 
250. Jia, J., Abudu, Y.P., Claude-Taupin, A., Gu, Y., Kumar, S., Choi, S.W., et al.: Galectins control mTOR in response to endomembrane damage. Mol. Cell. 70, 120-135 (2018)

251. Jia, J., Bissa, B., Brecht, L., Allers, L., Choi, S.W., Gu, Y., et al.: AMPK, a regulator of metabolism and autophagy, is activated by lysosomal damage via a novel galectin-directed ubiquitin signal transduction system. Mol. Cell. 77, 951-969 (2020)

252. Chen, H.Y., Fermin, A., Vardhana, S., Weng, I.C., Lo, K.F.R., Chang, E.Y., et al.: Galectin-3 negatively regulates TCR-mediated $\mathrm{CD} 4^{+} \mathrm{T}$-cell activation at the immunological synapse. Proc. Natl. Acad. Sci. USA. 106, 14496-14501 (2009)

253. Jia, J., Claude-Taupin, A., Gu, Y., Choi, S.W., Peters, R., Bissa, B., et al.: Galectin-3 coordinates a cellular system for lysosomal repair and removal. Dev. Cell. 52, 69-87 (2020)

254. Vietri, M., Radulovic, M., Stenmark, H.: The many functions of ESCRTs. Nat. Rev. Mol. Cell Biol. 21, 25-42 (2020)

255. Romero, A., Gabius, H.-J.: Galectin-3: is this member of a large family of multifunctional lectins (already) a therapeutic target? Expert Opin. Ther. Targets. 23, 819-828 (2019)

256. Kopitz, J., Vertesy, S., Andre, S., Fiedler, S., Schnolzer, M., Gabius, H.J.: Human chimera-type galectin-3: defining the critical tail length for high-affinity glycoprotein/cell surface binding and functional competition with galectin-1 in neuroblastoma cell growth regulation. Biochimie. 104, 90-99 (2014)

257. Wang, S.F., Tsao, C.H., Lin, Y.T., Hsu, D.K., Chiang, M.L., Lo, C.H., et al.: Galectin-3 promotes HIV-1 budding via association with Alix and Gag p6. Glycobiology. 24, 1022-1035 (2014)

258. Jia, J., Claude-Taupin, A., Gu, Y., Choi, S.W., Peters, R., Bissa, B., et al.: MERIT, a cellular system coordinating lysosomal repair, removal and replacement. Autophagy. 16(8), 1539-1541 (2020)

259. Miller, M.C., Ludwig, A.K., Wichapong, K., Kaltner, H., Kopitz, J., Gabius, H.J., et al.: Adhesion/growth-regulatory galectins tested in combination: evidence for formation of hybrids as heterodimers. Biochem. J. 475, 1003-1018 (2018)

260. Ledeen, R.W., Kopitz, J., Abad-Rodriguez, J., Gabius, H.J.: Glycan chains of gangliosides: Functional ligands for tissue lectins (siglecs/galectins). Prog. Mol. Biol. Transl. Sci. 156, 289-324 (2018)

261. Chiricozzi, E., Di Biase, E., Lunghi, G., Fazzari, M., Loberto, N., Aureli, M., et al.: Turning the spotlight on the oligosaccharide chain of GM1 ganglioside. Glycoconj. J. 38, 101-117 (2021)

262. Brandley, B.K., Schnaar, R.L.: Cell-surface carbohydrates in cell recognition and response. J. Leukoc. Biol. 40, 97-111 (1986)
263. Habermann, F., Kaltner, H., Higuero, A.M., García, Caballero, G., Ludwig, A.K., Manning, J.C., et al.: What cyto- and histochemistry can do to crack the sugar code. Acta Histochem. Cytochem. 54, 31-48 (2021)

264. Broussard, A.C., Boyce, M.: Life is sweet: the cell biology of glycoconjugates. Mol. Biol. Cell. 30, 525-529 (2019)

265. Weigel, P.H., Yik, J.H.: Glycans as endocytosis signals: the cases of the asialoglycoprotein and hyaluronan/chondroitin sulfate receptors. Biochim. Biophys. Acta. 1572, 341-363 (2002)

266. Park, E.I., Manzella, S.M., Baenziger, J.U.: Rapid clearance of sialylated glycoproteins by the asialoglycoprotein receptor. J. Biol. Chem. 278, 4597-4602 (2003)

267. Sancho, D., Reis, E., Sousa, C.: Signaling by myeloid C-type lectin receptors in immunity and homeostasis. Annu. Rev. Immunol. 30, 491-529 (2012)

268. de Witte, L., Nabatov, A., Pion, M., Fluitsma, D., de Jong, M.A., de Gruijl, T., et al.: Langerin is a natural barrier to HIV-1 transmission by Langerhans cells. Nat. Med. 13, 367-371 (2007)

269. Malhotra, R., Haurum, J.S., Thiel, S., Sim, R.B.: Binding of human collectins (SP-A and MBP) to influenza virus. Biochem. J. 304, 455-461 (1994)

270. Rempel, H., Calosing, C., Sun, B., Pulliam, L.: Sialoadhesin expressed on IFN-induced monocytes binds HIV-1 and enhances infectivity. PLoS One. 3, e1967 (2008)

271. O'Reilly, M.K., Tian, H., Paulson, J.C.: CD22 is a recycling receptor that can shuttle cargo between the cell surface and endosomal compartments of B cells. J. Immunol. 186, 1554-1563 (2011)

272. Earl, L.A., Bi, S., Baum, L.G.: N- and O-glycans modulate galectin-1 binding, CD45 signaling, and T cell death. J. Biol. Chem. 285, 2232-2244 (2010)

273. Spooner, R.A., Lord, J.M.: Ricin trafficking in cells. Toxins. 7, 49-65 (2015)

274. Chen, Y.F., Boland, C.R., Kraus, E.R., Goldstein, I.J.: The lectin Griffonia simplicifolia I-A4 (GS I-A4) specifically recognizes terminal alpha-linked $\mathrm{N}$-acetylgalactosaminyl groups and is cytotoxic to the human colon cancer cell lines LS174t and SW1116. Int. J. Cancer. 57, 561-567 (1994)

275. Cervin, J., Wands, A.M., Casselbrant, A., Wu, H., Krishnamurthy, S., Cvjetkovic, A., et al.: GM1 ganglioside-independent intoxication by Cholera toxin. PLoS Pathog. 14, e1006862 (2018)

Publisher's Note Springer Nature remains neutral with regard to jurisdictional claims in published maps and institutional affiliations. 